\title{
Microbial characterisation of the edible grasshopper Ruspolia differens in raw condition after wild-harvesting in Uganda
}

\author{
Geoffrey Ssepuuya $^{\mathrm{a}, \mathrm{b}, \mathrm{c}}$, Enya Wynants ${ }^{\mathrm{a}, \mathrm{b}}$, Christel Verreth ${ }^{\mathrm{b}, \mathrm{d}}$, Sam Crauwels ${ }^{\mathrm{b}, \mathrm{d}}$, Bart Lievens ${ }^{\mathrm{b}, \mathrm{d}}$, \\ Johan Claes $^{\mathrm{a}, \mathrm{b}}$, Dorothy Nakimbugwe ${ }^{\mathrm{c}}$, Leen Van Campenhout ${ }^{\mathrm{a}, \mathrm{b}, *}$ \\ ${ }^{a}$ KU Leuven, Department of Microbial and Molecular Systems (M2S), Lab4Food, Technology Campus Geel, Kleinhoefstraat 4, B-2440, Geel, Belgium \\ ${ }^{\mathrm{b}} \mathrm{KU}$ Leuven, Leuven Food Science and Nutrition Research Centre (LFoRCe), Leuven, Belgium \\ ${ }^{\mathrm{c}}$ Makerere University, Department of Food Technology and Nutrition, CAES, P. O. Box, 7062, Kampala, Uganda \\ ${ }^{\mathrm{d}}$ KU Leuven, Department of Microbial and Molecular Systems (M2S), Laboratory for Process Microbial Ecology and Bioinspirational Management (PME \& BIM), Campus \\ De Nayer, B-2860, Sint-Katelijne-Waver, Belgium
}

\section{A R T I C L E I N F O}

\section{Keywords:}

Edible insects

Ruspolia differens

Microbial counts

Bacterial composition

\begin{abstract}
A B S T R A C T
This research aimed at establishing the chemical intrinsic properties and the microbial quality of an edible grasshopper Ruspolia differens and the effect of its source (geographical area) in Uganda, trading point, swarming season and plucking on these parameters. The intrinsic properties of the grasshopper can support the growth of a wide variety of microorganisms. High counts of total aerobic microbes, Enterobacteriaceae, lactic acid bacteria, total aerobic spores, and yeasts and moulds were obtained. Metagenetic analyses yielded 1793 Operational Taxonomic Units (OTUs) belonging to 24 phyla. Actinobacteria, Bacteroidetes, Firmicutes, Fusobacteria and Proteobacteria were the most abundant phyla, while members of the genera Acinetobacter, Buttiauxella, Lactococcus, Staphylococcus and Undibacterium were the most abundant OTUs. A number of genera harbouring potential pathogens (Acinetobacter, Bacillus, Buttiauxella, Campylobacter, Clostridium, Staphylococcus, Pseudomonas and Neisseria) were identified. The geographical area, trading point, swarming season and plucking significantly influenced microbial counts and bacterial diversity. The high microbial counts predispose $R$. differens to fast microbial spoilage, while the presence of Clostridium and Campylobacter makes this grasshopper a potential source of food borne diseases. Further research should identify the specific spoilage microorganisms of $R$. differens and assess the characteristics of this grasshopper that support growth of food pathogens.
\end{abstract}

\section{Introduction}

Ruspolia differens Serville (Orthoptera: Tettigoniidae), also called 'nseenene' in the local language (Luganda), is an edible grasshopper and a delicacy in many African countries such as Angola, Cameroon, Central African Republic, Democratic Republic of Congo, Ghana, Ivory Coast, Madagascar, Malawi, Mauritius, Rwanda, South Africa, Tanzania, Uganda, Zambia and Zimbabwe (Brits and Thornton, 1981; Kelemu et al., 2015; Massa, 2015). The grasshoppers exist predominantly in two coloured polymorphs, being light green and light brown, though in total, six colour forms exist (Brits and Thornton, 1981; Mccrae, 1982). It is the closest relative to Ruspolia nitidula Scopoli (Orthoptera: Tettigoniidae) (Matojo, 2017; Matojo and Hosea, 2013), another grasshopper species with which it is often confused (Matojo and Njau, 2010). In Uganda, $R$. differens is harvested from the wild in two annual swarming seasons: from March to May and from November to December (Agea et al., 2008; Ssepuuya et al., 2016a). The aggregation of $R$. differens swarms in Uganda is attributed to a large build-up of local populations due to seasonal occurrences of grasslands (Brits and Thornton, 1981).

The need to establish the microbial quality of $R$. differens in an attempt to improve its overall quality and safety in Uganda has been expressed earlier (Ssepuuya et al., 2016a, 2016b). This is because, to a great extent, the numbers and types of microorganisms present in/on foods influence their microbial safety and shelf life (Amadi and Kiinkabari, 2016; Bokulich et al., 2016; Deá;k and Farkas, 2013). The microbial quality comprises both microbial counts as well as the microbial community composition. The latter is nowadays commonly determined by Next Generation Sequencing (NGS) techniques and has been applied to several foods including edible insects, to deepen the understanding of their quality and safety. For example, NGS of the 16S ribosomal RNA (rRNA) gene amplicons has been employed to monitor the impact of

\footnotetext{
* Corresponding author. Lab4Food, KU Leuven, Campus Geel, Kleinhoefstraat 4, B-2440, Geel, Belgium.

E-mail address: leen.vancampenhout@kuleuven.be (L. Van Campenhout).
} 
industrial post-harvest handling practices of freshly harvested yellow mealworms (Tenebrio molitor) (Wynants et al., 2017). Vandeweyer et al. (2017) used the technique to assess the effect of rearing cycles and production companies on the bacterial communities of mealworms ( $T$. molitor) and crickets (Acheta domesticus and Gryllodes sigillatus).

The microbial community of foods, such as $R$. differens, may likely be influenced by the environment from which it is harvested and by the post-harvest handling conditions and processes (Gomba et al., 2017; Leff and Fierer, 2013). In Uganda, following harvesting using light traps (Ssepuuya, 2010), $R$. differens is manually (by hands) removed from the drums, packaged into aerated polythene/nylon/sisal bags and transported to trading points. At the trading points, raw grasshoppers are presented either as whole (non-plucked) insects or as ready-to-cook plucked insects (with the wings, legs and antennae removed), often on roadside informal and/or fresh food markets. Plucking is done manually, mostly by women and children, using several aids such as water, wood ash and cassava or maize flour. These practices possibly influence the type and number of microorganisms in/on $R$. differens. Fresh grasshoppers (plucked or non-plucked) are obtainable from the market within 8-24 h after harvesting before being heat processed and stored. Plucked grasshoppers are deep fried, drained to remove excess oil, cooled and stored in cardboard boxes. Non-plucked grasshoppers are boiled in salty water, drained, cooled, and sun-dried, and stored in a clean dry place, free of rodents and other contaminating substances or organisms. Other processing methods are detailed by Ssepuuya et al. (2016a).

Using both microbial culture-dependent and/or microbial cultureindependent methods, a few studies have investigated the microbial community and quality of edible insects, especially in Europe (Klunder et al., 2012; Megido et al., 2017; Osimani et al., 2016; Stoops et al., 2016; Vandeweyer et al., 2017; Wynants et al., 2017). However, no such published information exists for most edible insects in Africa, including $R$. differens. Therefore, the aim of this study was to apply both microbial culture-dependent and microbial culture-independent techniques to determine the microbial quality and community of raw $R$. differens grasshoppers. The study further assessed the effect of four factors (geographical area, swarming season, trading point and plucking) on the intrinsic properties, microbial quality and bacterial diversity of raw wild-harvested $R$. differens. These factors possibly influence the type and load of microorganisms and hence the post-harvest quality and safety of $R$. differens for human consumption.

\section{Materials and methods}

\subsection{Sampling}

From each of the three major grasshopper harvesting geographical areas in Uganda (Masaka, Kampala and Fort Portal), three major grasshopper harvesting and trading points were identified (Fig. 1). From each of these 3 points in a geographical area, a $200 \mathrm{~g}$ sample of winged grasshoppers was collected from 4 drums selected randomly (50 $\mathrm{g}$ from each drum at each point) into a sterile sample collection plastic container. Similarly, a $200 \mathrm{~g}$ sample of plucked grasshoppers was collected from 4 randomly selected selling points $(50 \mathrm{~g}$ from each selling point) into a sterile sample collection container. The containers were placed in a cool box, covered with flaked ice $\left(4-7^{\circ} \mathrm{C}\right)$ until classical microbial analyses. In a sterile environment, $30 \mathrm{~g}$ was taken from each $200 \mathrm{~g}$ sample and stored in a sterile bag at $-18^{\circ} \mathrm{C}$ until metagenetic analyses and determination of intrinsic properties.

\subsection{Measurement of intrinsic properties}

Samples were thawed overnight in a refrigerator before analysis. For each sample, $30 \mathrm{~g}$ of $R$. differens was pulverized using a hand-held blender (Silver Crest, 600 W, speed 4, 3 min) into a paste. The paste was mixed with thrice its weight of ultra-pure water and the $\mathrm{pH}$ was measured using a pH electrode (Portamess 911, Knick, Germany, with SI analytics electrode, Germany). To measure water activity, a $5 \mathrm{~cm}$ diameter plastic container was filled with the grasshopper paste and placed in the measuring chamber of the water activity meter (LabMaster $\mathrm{a}_{\mathrm{w}}$, Novasina, Switzerland). The result was noted when the water activity and temperature $\left(25^{\circ} \mathrm{C}\right)$ were stable. To measure the moisture content, a forced draft oven method (Nielsen, 2010), was used. Briefly, $5 \mathrm{~g}$ of a sample was measured to the nearest $0.0001 \mathrm{~g}$ into a dry pre-weighed aluminum dish in triplicate. The dishes were transferred to an oven (UF 110, Memmert, Schwabach, Germany) at $105^{\circ} \mathrm{C}$. After $16 \mathrm{~h}$, they were transferred into a dessicator, left to cool for $1 \mathrm{~h}$ and re-weighed. Moisture content was expressed as a percentage difference between the weight of the dry and wet samples (Nielsen, 2010). Triplicate samples for each of the plucked and non-plucked samples of $R$. differens from each of the three trading points in the three geographical areas of source were analysed for moisture content and water activity in the March-May and November-December swarming seasons of 2016. For $\mathrm{pH}$, one sample from each trading point in a geographical area was analysed.

\subsection{Culture-dependent microbiological analysis}

Non-plucked grasshoppers were sedated by storing them at $4-7{ }^{\circ} \mathrm{C}$ for $2 \mathrm{~h}$. From each non-plucked or plucked sample, $30 \mathrm{~g}$ were pulverized as described before. An aliquot of $5 \mathrm{~g}$ of the pulverized sample was weighed into a sterile stomacher bag and diluted 10 times with sterile peptone water ( $1 \mathrm{~g}$ of the powder medium, Biokar Biokar diagnostics, France and $8.5 \mathrm{~g}$ of salt dissolved in $1 \mathrm{~L}$ of distilled water) for $1 \mathrm{~min}$ at $230 \mathrm{rpm}$ in a stomacher (Seward stomacher, 400 circulator, Wagatech International). Serial dilutions (from $10^{-1}$ to $10^{-4}$ for aerobic bacterial spores, from $10^{-3}$ to $10^{-6}$ for yeasts and moulds, from $10^{-4}$ to $10^{-9}$ for aerobic mesophilic microorganisms, lactic acid bacteria and Enterobacteriaceae) were prepared to pour onto plates using approximately $15 \mathrm{ml}$ per plate of various media according to Dijk et al. (2015): aerobic mesophilic microorganisms were counted on Plate Count Agar (PCA, Biokar diagnostics, France) after incubation for 3 days at $30^{\circ} \mathrm{C}$. After a heat treatment step of $10 \mathrm{~min}$ at $80^{\circ} \mathrm{C}$ to kill the vegetative cells, aerobic bacterial spores were counted using Plate Count Agar (PCA, Biokar diagnostics, France) after incubation at $37^{\circ} \mathrm{C}$ for $48 \mathrm{~h}$. Enterobacteriaceae were counted using Violet Red Glucose Bile Agar with an overlay (VRBGA, Biokar diagnostics, France) after incubation at $37^{\circ} \mathrm{C}$ for $24 \mathrm{~h}$. Lactic acid bacteria (LAB) were counted using de Man Ragosa Sharpe Agar (MRS) with an overlay (MRS, Biokar diagnostics, France) after incubation at $30^{\circ} \mathrm{C}$ for $48 \mathrm{~h}$. Yeasts and moulds were counted using Dichloran Glycerol Agar (DG 18, Pronadisa, Spain) mixed with $175 \mathrm{ml}$ of glycerol (HiMedia Laboratories Pvt. Ltd, India) per litre of medium, after incubation at $30^{\circ} \mathrm{C}$ for $72 \mathrm{~h}$. In triplicate, three plucked and non-plucked samples of $R$. differens from each of the three trading points in the three geographical areas of source were analysed in both the March-May and November-December swarming seasons of 2016.

\subsection{Metagenetic analyses}

Following thawing as indicated above, samples for metagenetic analysis were pulverized and subjected to high-throughput 16S rRNA gene sequencing using the Illumina MiSeq platform. Genomic DNA was extracted from two replicate samples $(0.2 \mathrm{~g})$ in duplicate using the Powersoil DNA Isolation Kit (MO BIO Laboratories, Carlsbad, California, USA). Subsequently, the two DNA-extracts were pooled and subjected to PCR amplification of the V4 region of the 16S rRNA gene. PCR amplification was performed by barcode-labelled versions (dual index strategy; Kozich et al., 2013) of the primers 515F (5'- GTGCCA GCMGCCGCGGTAA-3') and 806R (5'-GGAC-TACHVGGGTWTCTAAT-3') (Caporaso et al., 2011), (Table S1, Supplementary Information). 


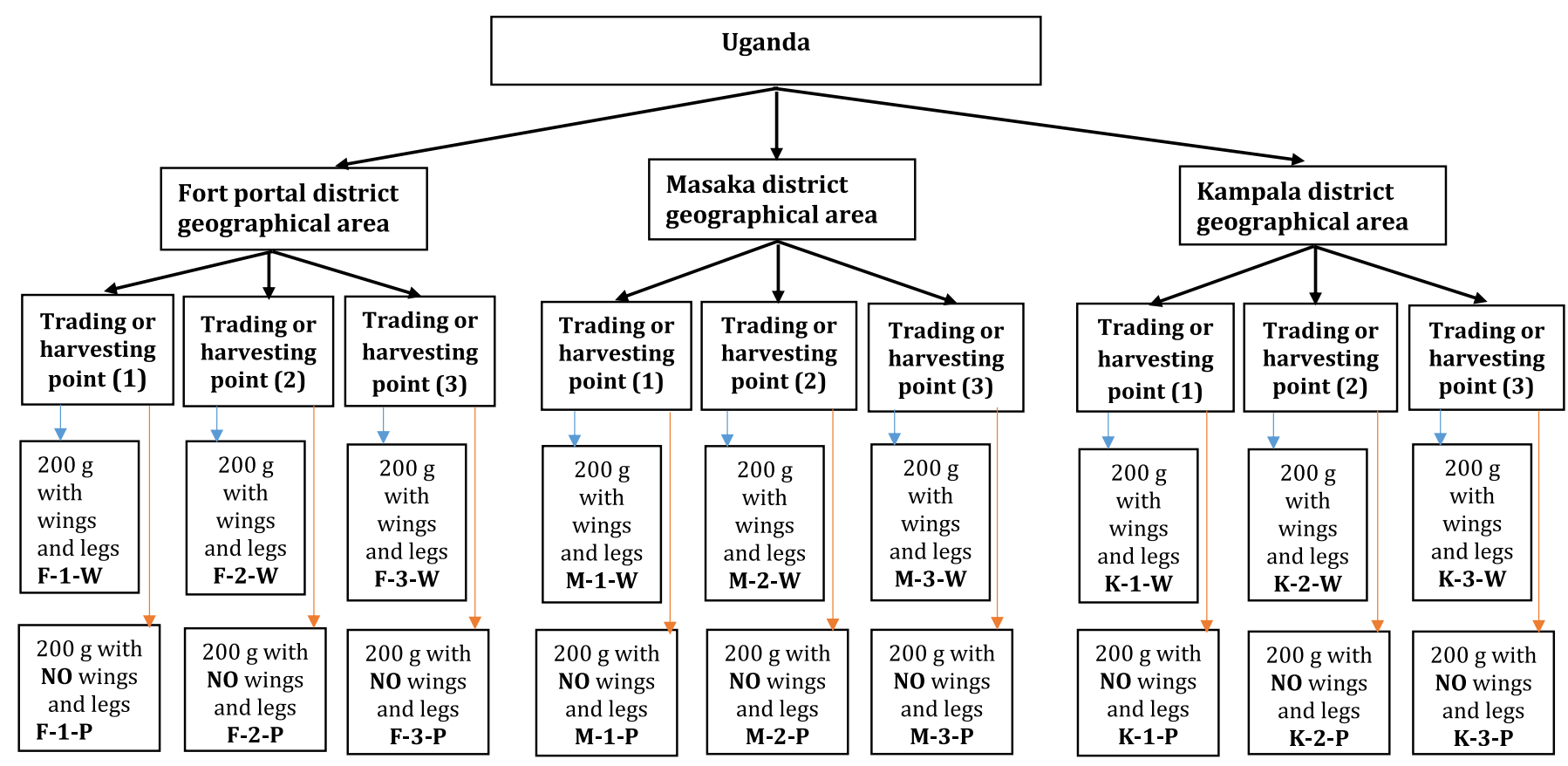

Fig. 1. Sampling plan for plucked and non-plucked Ruspolia differens in Uganda in the two swarming seasons of March-May and November-December of the year 2016.

Briefly, PCR reactions were performed in duplicate in a $20 \mu \mathrm{l}$ reaction volume, containing $150 \mathrm{mM}$ of each dNTP, $0.5 \mathrm{mM}$ of each primer, one unit of Titanium Taq DNA polymerase (Clontech, Saint-Germainen-Laye, France), 1x Titanium Taq PCR buffer, and $1 \mu \mathrm{l}$ 1:10 diluted DNA. The PCR amplification protocol involved an initial denaturation at $95{ }^{\circ} \mathrm{C}$ for $2 \mathrm{~min}$, followed by 30 cycles of denaturation at $95^{\circ} \mathrm{C}$ for $45 \mathrm{~s}$, primer annealing at $59^{\circ} \mathrm{C}$ for $45 \mathrm{~s}$, and primer extension at $72{ }^{\circ} \mathrm{C}$ for $45 \mathrm{~s}$, and a final extension of $10 \mathrm{~min}$ at $72{ }^{\circ} \mathrm{C}$. Next, amplicons were purified by Agencourt AMPure XP beads (Beckman Coulter, Brea, CA, USA), quantified using the Qubit fluorometer (HS reaction kit, Invitrogen, Carlsbad, CA, USA), and combined into a library in equimolar concentrations. Subsequently, the library was subjected to an ethanol precipitation and loaded onto an agarose gel. Next, the target band (c. $250 \mathrm{bp}$ ) was excised and the DNA was purified and diluted to a $2 \mathrm{nM}$ concentration and sequenced at the Center of Medical Genetics Antwerp (University of Antwerp, Belgium) using an Illumina MiSeq sequencer (V2 500 cycle kit, Illumina, San Diego, CA, USA). Sequences were received in the format of a de-multiplexed FASTQ file. Paired-end reads were merged with a maximum of five mismatches using USEARCH (v.9.2.64) (Edgar, 2013) to form consensus sequences and truncated at the $250^{\text {th }}$ base. Shorter reads or reads with a total expected error threshold above 0.10 for all bases after truncation were discarded. Next, the "classify.seqs" and "remove.lineage" commands in Mothur (v1.39.3; Edgar, 2013) and the Silva database (v123; Gurevich et al., 2013) were used to identify and remove potential mitochondrial, chloroplast, archaeal and eukaryote contaminants. Due to uneven sequencing depth, the number of sequences was rarefied to about 28,950 sequences per sample. Samples that yielded too few sequences were discarded from further analysis. Remaining sequences were grouped into operational taxonomic units (OTUs) based on a 3\% sequence dissimilarity cut-off using the UPARSE greedy algorithm in USEARCH, during which chimeric sequences were also removed (Edgar, 2013), as the global singletons (i.e. OTUs representing only a single sequence in the entire dataset), minimising the risk of retaining sequences from sequencing errors (Brown et al., 2015; Waud et al., 2014). The taxonomic origin of each OTU was determined with the SINTAX algorithm implemented in USEARCH (Edgar, 2016) based on the Silva database v123 (LTP v123). Taxonomic assignments were considered reliable when bootstrap confidence values exceeded 0.80 . Sequence data have been deposited in the Sequence Read Archive under BioProject accession PRJNA453689 (accession numbers SAMN09010838 SAMN09010908).

\subsection{Statistical analysis}

Statistical Package for Social Scientists (SPSS) for windows (Version 20, IBM Corporation, Armonk, New York) software was used to perform statistical analyses. Descriptive statistics were used to obtain means and standard deviations. ANOVA was used to determine the effect of (i) geographical area of source, swarming season, plucking and trading point on selected microbial counts (Total Aerobic Count (TAC), Enterobacteriaceae, lactic acid bacteria, aerobic bacterial spores and yeasts and moulds) and (ii) alpha diversity indices (Richness, Chao1, Shannon-Wiener and Evenness) of $R$. differens. Evenness was calculated according to the formula $-\Sigma p_{i} \operatorname{In}\left(p_{i}\right) / \ln S$ where $p_{i}$ is the relative frequency of species $i$ in the community and $S$ is the number of species in the community (Di Bitetti, 2000). Mean separation was obtained by the Tukey's option of the ANOVA test. For all tests, a significance level of $\leq 0.05$ was considered. Based on the sequencing data, nonmetric multidimensional scaling (NMDS) was performed using the $\mathrm{R}$ packages Vegan (v.2.43) (R Development Core Team, 2013).

\section{Results and discussion}

\subsection{Intrinsic properties of raw wild-harvested Ruspolia differens}

The effects of geographical area of source, swarming season, plucking and trading point on moisture content, water activity and $\mathrm{pH}$ were investigated. Results are presented in Table 1. Overall, $R$. differens had an average moisture content of $51.11 \pm 4.90 \%$, an average water activity of $0.976 \pm 0.003$ and an average $\mathrm{pH}$-value of $6.33 \pm 0.20$. The observed moisture content range of $R$. differens, being between 43.96 and $61.32 \%$, was similar to that observed in an earlier study (47-55\%) for green and brown $R$. differens polymorphs (Ssepuuya et al., 2016a), though lower than that observed in $R$. differens collected from Kenya (60-72\%) (Kinyuru et al., 2009). The moisture content was also 
Table 1

Selected intrinsic properties of raw plucked and non-plucked Ruspolia differens from three sourcing geographical areas in the two swarming seasons.

\begin{tabular}{|c|c|c|c|c|c|c|}
\hline \multirow[t]{2}{*}{ Sample } & \multicolumn{2}{|c|}{ Moisture content (\%) } & \multicolumn{2}{|l|}{ Water activity $\left(\mathrm{a}_{\mathrm{w}}\right)$} & \multicolumn{2}{|l|}{$\mathrm{pH}$} \\
\hline & Mar-May & Nov-Dec & Mar-May & Nov-Dec & Mar-May & Nov-Dec \\
\hline M-1-W & $52.00 \pm 0.39^{\mathrm{ac}}$ & $53.45 \pm 0.23^{\mathrm{bc}}$ & $0.976 \pm 0.002^{\mathrm{ac}}$ & $0.976 \pm 0.002^{\mathrm{ac}}$ & 6.04 & 6.38 \\
\hline M-2-W & $48.97 \pm 0.09^{\mathrm{ac}}$ & $49.04 \pm 0.11^{\mathrm{ac}}$ & $0.980 \pm 0.002^{\mathrm{ac}}$ & $0.978 \pm 0.004^{\mathrm{ac}}$ & 6.45 & 6.17 \\
\hline M-3-W & $49.99 \pm 0.52^{\mathrm{ac}}$ & $50.89 \pm 0.25^{\mathrm{ac}}$ & $0.975 \pm 0.001^{\mathrm{ac}}$ & $0.976 \pm 0.002^{\mathrm{ac}}$ & 6.39 & 6.27 \\
\hline$M-W$ & $50.32 \pm 1.38^{x}$ & $51.13 \pm 1.93^{y}$ & $0.977 \pm 0.023^{x}$ & $0.977 \pm 0.002^{x}$ & & \\
\hline M-1-P & $47.44 \pm 0.12^{\mathrm{ad}}$ & $50.31 \pm 1.82^{\mathrm{ad}}$ & $0.977 \pm 0.006^{\mathrm{ac}}$ & $0.975 \pm 0.002^{\mathrm{ac}}$ & 6.50 & 6.58 \\
\hline M-2-P & $45.24 \pm 0.22^{\mathrm{ad}}$ & $45.15 \pm 0.01^{\mathrm{ad}}$ & $0.974 \pm 0.006^{\mathrm{ac}}$ & $0.978 \pm 0.001^{\mathrm{ac}}$ & 6.61 & 6.15 \\
\hline M-3-P & $48.89 \pm 0.17^{\mathrm{ac}}$ & $48.25 \pm 0.33^{\mathrm{bd}}$ & $0.977 \pm 0.001^{\mathrm{ac}}$ & $0.976 \pm 0.001^{\mathrm{ac}}$ & 6.44 & 5.94 \\
\hline$M-P$ & $47.21 \pm 1.63^{x}$ & $47.90 \pm 2.43^{x}$ & $0.976 \pm 0.003^{x}$ & $0.976 \pm 0.001^{x}$ & & \\
\hline $\mathrm{K}-1-\mathrm{W}$ & $60.06 \pm 0.07^{\mathrm{ac}}$ & $56.52 \pm 0.13^{b c}$ & $0.987 \pm 0.000^{\mathrm{ac}}$ & $0.977 \pm 0.002^{\mathrm{ac}}$ & 6.44 & 5.75 \\
\hline $\mathrm{K}-2-\mathrm{W}$ & $60.92 \pm 0.07^{\mathrm{ac}}$ & $56.57 \pm 0.20^{\mathrm{bc}}$ & $0.977 \pm 0.002^{\mathrm{ac}}$ & $0.975 \pm 0.001^{\mathrm{ac}}$ & 6.36 & 6.09 \\
\hline $\mathrm{K}-3-\mathrm{W}$ & $61.32 \pm 0.23^{\mathrm{ac}}$ & $53.41 \pm 0.21^{\mathrm{bc}}$ & $0.976 \pm 0.001^{\mathrm{ac}}$ & $0.976 \pm 0.003^{\mathrm{ac}}$ & 6.38 & 6.59 \\
\hline$K-W$ & $60.94 \pm 0.30^{y}$ & $55.51 \pm 1.57^{x}$ & $0.977 \pm 0.001^{x}$ & $0.976 \pm 0.002^{x}$ & & \\
\hline K-1-P & $54.66 \pm 0.03^{\mathrm{ad}}$ & $48.75 \pm 0.56^{\mathrm{bd}}$ & $0.975 \pm 0.001^{\mathrm{ad}}$ & $0.975 \pm 0.003^{\mathrm{ac}}$ & 5.99 & 6.28 \\
\hline $\mathrm{K}-2-\mathrm{P}$ & $55.23 \pm 0.17^{\mathrm{ad}}$ & $51.34 \pm 0.13^{\mathrm{bd}}$ & $0.978 \pm 0.004^{\mathrm{ac}}$ & $0.973 \pm 0.002^{\mathrm{ac}}$ & 6.64 & 6.21 \\
\hline K-3-P & $53.42 \pm 0.21^{\mathrm{ad}}$ & $54.21 \pm 0.16^{\mathrm{bd}}$ & $0.976 \pm 0.003^{\mathrm{ac}}$ & $0.974 \pm 0.003^{\mathrm{ac}}$ & 6.45 & 6.26 \\
\hline$K-P$ & $54.70 \pm 1.64^{\mathrm{y}}$ & $49.02 \pm 1.92^{x}$ & $0.976 \pm 0.003^{x}$ & $0.975 \pm 0.003^{x}$ & & \\
\hline F-1-W & $53.96 \pm 0.34^{\mathrm{ac}}$ & $49.74 \pm 0.09^{b c}$ & $0.979 \pm 0.002^{\mathrm{ac}}$ & $0.975 \pm 0.002^{\mathrm{ac}}$ & 6.60 & 6.22 \\
\hline F-2-W & $54.59 \pm 0.22^{\mathrm{ac}}$ & $49.13 \pm 0.09^{b c}$ & $0.975 \pm 0.001^{\mathrm{ac}}$ & $0.973 \pm 0.002^{\mathrm{ac}}$ & 6.42 & 6.38 \\
\hline F-3-W & $55.38 \pm 0.18^{\mathrm{ac}}$ & $50.09 \pm 0.09^{b c}$ & $0.980 \pm 0.002^{\mathrm{ac}}$ & $0.977 \pm 0.002^{\mathrm{ac}}$ & 6.56 & 6.38 \\
\hline$F-W$ & $54.65 \pm 0.66^{z}$ & $49.66 \pm 0.43^{\mathrm{y}}$ & $0.977 \pm 0.002^{x}$ & $0.976 \pm 0.002^{x}$ & & \\
\hline F-1-P & $45.75 \pm 0.09^{\mathrm{ad}}$ & $40.75 \pm 0.39^{\mathrm{bd}}$ & $0.966 \pm 0.005^{\mathrm{ad}}$ & $0.978 \pm 0.001^{\mathrm{bc}}$ & 6.48 & 6.42 \\
\hline F-2-P & $46.52 \pm 0.11^{\mathrm{ad}}$ & $46.47 \pm 0.73^{\mathrm{ac}}$ & $0.973 \pm 0.002^{\mathrm{ac}}$ & $0.973 \pm 0.002^{\mathrm{ac}}$ & 6.45 & 6.24 \\
\hline F-3-P & $53.48 \pm 0.58^{\mathrm{ad}}$ & $43.96 \pm 0.51^{\mathrm{bd}}$ & $0.972 \pm 0.002^{\mathrm{ad}}$ & $0.976 \pm 0.003^{\mathrm{ac}}$ & 6.16 & 6.26 \\
\hline$F-P$ & $48.59 \pm 3.69^{x}$ & $43.73 \pm 4.45^{\mathrm{y}}$ & $0.970 \pm 0.004^{\mathrm{y}}$ & $0.976 \pm 0.003^{x}$ & & \\
\hline
\end{tabular}

1, 2, 3: the trading points per region.

M, K, P: the three regions namely, Masaka, Kampala and Fort portal.

$\mathrm{W}, \mathrm{P}$ : the non-plucked and plucked treatments.

a,b Values carrying different superscripts horizontally for every parameter are significantly different across seasons.

${ }^{\mathrm{c}, \mathrm{d}}$ For each trading point in a region, values carrying different superscripts in a column are significantly different due to plucking.

${ }^{\mathrm{xyz}}$ Values in a column of the same treatment carrying different superscripts are significantly different due to geographical area.

lower than that of other comparable protein sources such as meat and fish (Ssepuuya et al., 2016a). However, it was similar to that of other edible insect species such as T. molitor and A. domesticus (Finke, 2015). The lower moisture content translated into a higher dry matter content implying a higher amount of nutrients available for microbial growth. There are no studies reporting on the water activity of $R$. differens to date. However, its water activity range of $0.975-0.987$ is similar to that of other edible insects such as the lesser mealworm Alphitobius diaperinus (0.98-0.99), A. domesticus (0.97) and other high quality protein sources such as fish and meat (Schmidt and Fontana, 2007; Vandeweyer et al., 2018; Wynants et al., 2018). The $\mathrm{pH}$ of $R$. differens is slightly acidic and ranged between 5.75 and 6.60 (Sperber and Doyle, 2009). Further research is required to investigate this quite wide range in $\mathrm{pH}$. However, this $\mathrm{pH}$ most likely favors bacterial growth since most bacteria grow best close to or at a neutral pH of 7 (Sharma, 2007; Spellman and Stoudt, 2013).

The geographical area of source, swarming season, plucking and trading point all had an influence on moisture content and water activity, though inconsistently (Table 1). Non-plucked grasshoppers from Kampala had the highest moisture content though not necessarily the highest water activity. Non-plucked $R$. differens generally had an equal or higher and at sometimes significantly different moisture content compared to plucked $R$. differens. It is therefore possible that the wings, legs and antennae removed during plucking contain a significant amount of water that is lost upon removal and/or that plucking causes physical damage accelerating dehydration. This loss of water increases the proportion of the dry matter content and therefore results in a higher proportion of nutrients. Similar to earlier observations (Ssepuuya et al., 2016a), irrespective of the plucking, $R$. differens in the March-May swarming season had a lower moisture (albeit not always significantly different), compared to $R$. differens in the
November-December swarming season. Since $R$. differens swarm in about 1.5-2 months after the start of the rainy season (Mccrae, 1982), the quality and abundance of plant food (mainly cereal grasses) available during growth and before swarming may influence its composition (Ssepuuya et al., 2018). These differences in moisture content due to geographical area of source and plucking, however, did not result in significant changes in water activity. The average water activity (0.975-0.987) observed remained above 0.9, a value above which all types of microorganisms can flourish (Steele, 2004). Therefore, these differences in moisture content are not expected to influence microbial counts.

\subsection{Culture-dependent analyses of the microbial quality of Ruspolia differens}

As presented in Fig. 2, overall, $R$. differens exhibited an average total aerobic count range being from 8.38 to $9.41 \mathrm{log} \mathrm{cfu} / \mathrm{g}$; from 6.89 to $7.83 \mathrm{log} \mathrm{cfu} / \mathrm{g}$ for Enterobacteriaceae; from 7.99 to $9.11 \mathrm{log} \mathrm{cfu} / \mathrm{g}$ for lactic acid bacteria; from 3.75 to $4.87 \mathrm{log} \mathrm{cfu} / \mathrm{g}$ for aerobic bacterial spores and from 5.77 to $7.12 \mathrm{log} \mathrm{cfu} / \mathrm{g}$ of yeasts and moulds (Fig. 2 and Table S2). Currently, there are no studies detailing the microbial quality of raw wild-harvested $R$. differens grasshoppers. However, the microbial counts of $R$. differens are comparable to those of other edible insect species for the assayed groups of microorganisms. Except for the total number of aerobic bacterial spores which was substantially higher, all the bacterial counts were either slightly higher or similar to those observed in fresh A. diaperinus, A. domesticus, and in the grasshopper Locusta migratoria (Klunder et al., 2012; Megido et al., 2017; Stoops et al., 2016; Wynants et al., 2018).

The effect of the geographical area of source, swarming season, plucking and trading point on five bacterial counts of food quality 


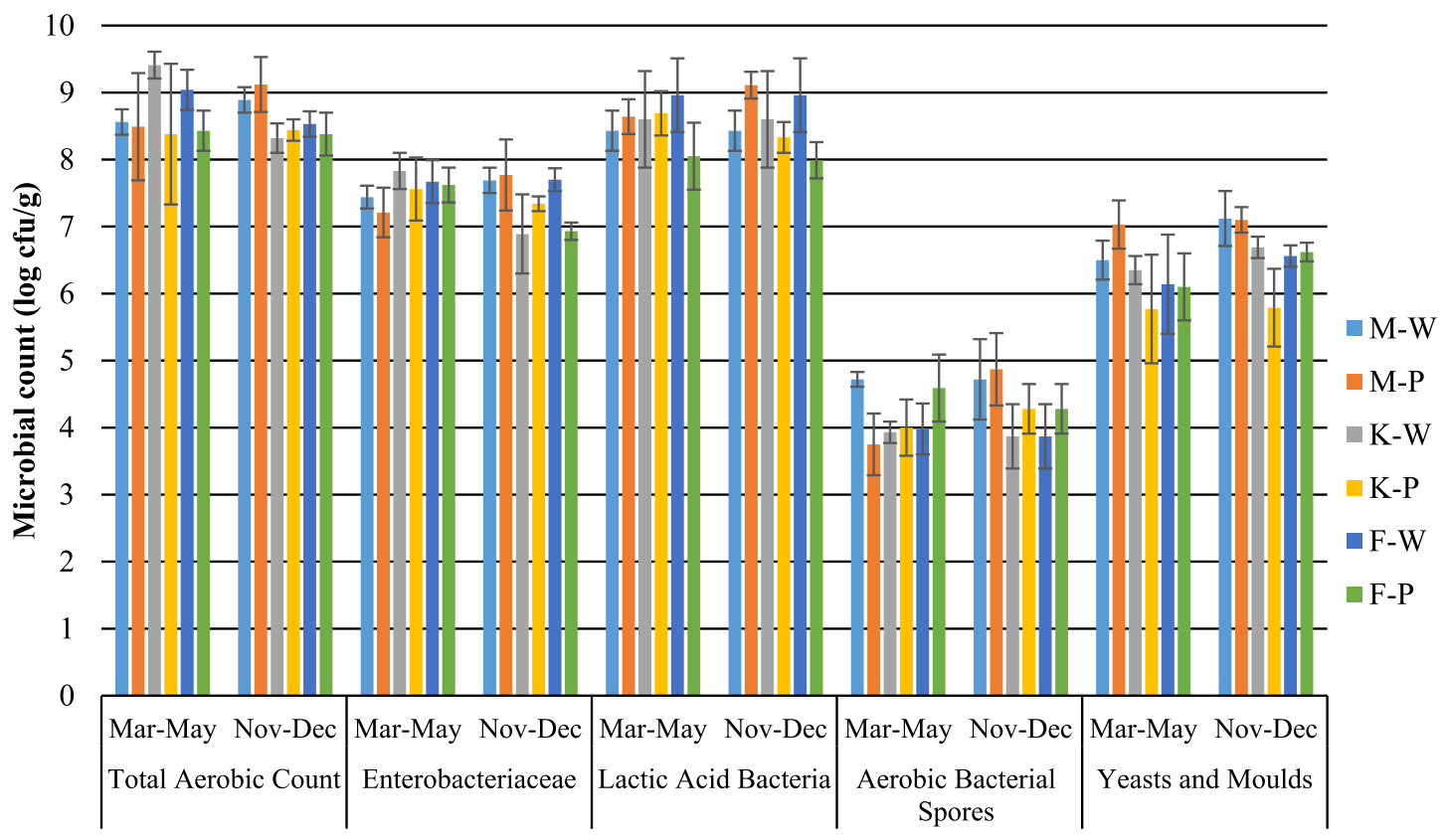

Season, Group of microorganisms

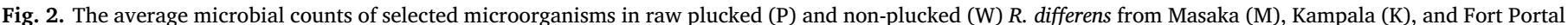

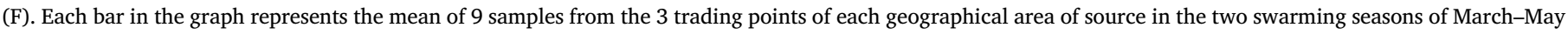
and November-December of the year 2016.

concern was investigated. The geographical area of source had a significant influence on the bacterial counts. With the exception of $R$. differens from Kampala that had the highest average total aerobic count $(9.41 \pm 0.22 \log \mathrm{cfu} / \mathrm{g}), R$. differens from Masaka had the highest average counts for Enterobacteriaceae $(7.83 \pm 0.27 \mathrm{log} \mathrm{cfu} / \mathrm{g})$, lactic acid bacteria $(9.11 \pm 0.20 \log \mathrm{cfu} / \mathrm{g})$, aerobic bacterial spores $(4.87 \pm 0.54 \log \mathrm{cfu} / \mathrm{g})$, and yeasts and moulds $(7.12 \pm 0.41 \mathrm{log} \mathrm{cfu} /$ g) (Table S2). For each season, the values mentioned above were on many occasions significantly higher than the bacterial counts of $R$. differens from Fort Portal and Kampala. This may be explained by differences in the way grasshoppers are handled after harvest at the harvesting and/or trading points of the different geographical areas of source. However, further research into the effects of the geographical area of source on the bacterial counts is thus necessary.

Swarming season, plucking and trading point also significantly influenced the counts of all groups of bacteria investigated, but without a consistent positive or negative pattern (Table S2). For example, in the March-May and November-December swarming seasons, the total aerobic count of non-plucked $R$ differens from trading points 2 and 3 in Masaka were not significantly different. However, $R$. differens from trading point 1 in the November-December swarming season had a significantly higher count than that in the March-May swarming season. In Kampala, the non-plucked $R$. differens samples in the March-May swarming season had significantly higher total aerobic counts than those in the November-December swarming season for all 3 trading points. This inconsistence regarding the effect of plucking on the total aerobic count was also observed for Fort Portal. The same scenario was observed regarding the effect of trading point, swarming season, and plucking on other bacterial counts (Enterobacteriaceae, lactic acid bacteria, total aerobic spores, and yeasts and moulds). This implies that the statistical differences observed are not the result of swarming season, plucking or trading point, but rather random. Similarly, there were no consistent microbiological differences ( $\geq 1 \log$ unit difference) among bacterial counts observed as a result of the effects of swarming season, plucking and trading point. Overall, the difference between the lowest and highest counts within each group of microorganisms was highest for Enterobacteriaceae (a 2-log unit difference) and lowest for other bacterial counts (l-log unit difference) (Table S2). Due to the absence of microbiological criteria for fresh edible insects in general and for $R$. differens in particular, it cannot be ascertained that the observed microbiological differences would influence its microbial quality.

The total aerobic count represents one of the microbial guidelines used for assessing the overall quality of fresh food, with high total aerobic counts associated with rapid spoilage and unsafe fresh foods (Hui and Sherkat, 2005; Monaghan, 2010). Notably, the aerobic spore count in $R$. differens was consistently higher than that observed in other edible insects such as T. molitor, A. domesticus and G. sigillatus in Belgium (Stoops et al., 2016; Vandeweyer et al., 2017) and accordingly, in the latter studies the spore count did not highly contribute to the observed total aerobic counts. Besides the difference in the type of edible insects (insect matrix), these differences in total aerobic spore count could be attributed to the differences in climate (especially temperature) between Belgium and the tropical Uganda. Empirical evidence is however required to confirm this hypothesis.

Similar to general data on fish and beef, $R$ differens has a high water activity ( $>0.9$ ), adequate sources of energy and an abundance of nutrients (nitrogen, vitamins, and minerals) required for survival and rapid multiplication of microorganisms (Harrison, 2017; Hui et al., 2001; Lovell, 2012; Zimmermann and Burgerstein, 2001). Hence, the microbial criteria for fish and meat could be used as a benchmark for assessing the fresh microbial quality of insects such as $R$. differens. In Belgium, according to an advice document from the Superior Health Council (SHC) and the Federal Agency for the Safety of the Food Chain (FASFC), process hygiene criteria for minced meat described in EU Regulation (EC) No. 1441/2007 can be used for edible insects (Stoops et al., 2016). This criterion defines, for five samples of one batch to be investigated, $5 \times 10^{5} \mathrm{cfu} / \mathrm{g}$ as the lower limit and $5 \times 10^{6} \mathrm{cfu} / \mathrm{g}$ as the upper limit, both of which are about $1-2 \log$ units lower than the average total aerobic count observed in $R$. differens. However, the Advice document also indicates that: "based on the (limited) information available in the literature, it is difficult to achieve this criterion for raw 
insects. Nevertheless, this criterion can be used as a reference value and ought to be attainable after heat treatment in a controlled and hygienically executed process." Whereas this was not included in this study, it is plausible that a proper heat treatment of the grasshoppers can reduce their microbial counts to below the aforementioned lower limit and hence heat treatment is advised to be performed prior to consumption (immediately after heat treatment). In Uganda, the upper microbial limit for the total aerobic count of fresh fish is $10^{5} \mathrm{cfu} / \mathrm{g}$, though the number of samples per batch to be investigated are not stated in the criteria (ULII, 2008). These microbial limits imply that the total aerobic count of $R$. differens was 1-2 log units higher than levels acceptable in similar products, which may be a threat to its quality and food safety. However, given that these high counts were associated with raw and unspoiled $R$. differens, it implies that there is a need to define new microbial criteria for fresh and/or heat-treated insects. They should not only include limits for total aerobic counts, but also for food safety and quality indicator organisms (e.g. E. coli as an indicator of fecal contamination) for specific edible insects such as $R$. differens and its different edible forms (whole, ground, etc.).

\subsection{Metagenetic analyses}

Next generation sequencing targeting part of the 16S rRNA gene was used to characterize the bacterial community of wild-harvested fresh $R$. differens. This yielded a total of 1792 Operational Taxonomic Units (OTUs) belonging to 24 phyla (Table S3). Overall, Proteobacteria (35.03-46.43\%), Firmicutes (14.02-26.46\%), Actinobacteria (9.62-21.94\%), Bacteroidetes (2.68-19.89\%) and Fusobacteria (0.41-12.50\%) were the most abundant phyla in $R$. differens, irrespective of the geographical area source (Fig. 3). The most abundant OTUs in the three geographical areas belonged to the Proteobacteria and Firmicutes phyla. Firmicutes and Proteobacteria were also the most abundant phyla in L. migratoria (Stoops et al., 2016), T. molitor larvae (Wynants et al., 2017), A. diaperinus larvae (Wynants et al., 2018) and A. domesticus (Vandeweyer et al., 2017). Unlike in L. migratoria and T. molitor larvae where the relative abundance of the Bacteroidetes was low, it was relatively high in A. domesticus (Vandeweyer et al., 2017), as it is in $R$. differens. Whereas Wynants et al. $(2017,2018)$ reported a low relative abundance of Actinobacteria in T. molitor larvae and A. diaperinus, Stoops et al. (2016) reported a higher relative abundance of $26.9 \%$ in $T$. molitor, the latter being slightly higher than the highest Actinobacteria abundance (21.95\%) observed in this study. Therefore, it is possible that edible insects can be colonized by similar bacterial phyla, though the phylum Fusobacteria has not been identified in any other edible insect to date than $R$. differens.

OTU richness ranged from 140 to 702 OTUs, with an average of $265 \pm 125$ OTUs per sample. On average, the observed number of OTUs in $R$. differens is higher than that in L. migratoria and T. molitor larvae but lower than that observed in fresh A. domesticus (Stoops et al., 2016; Vandeweyer et al., 2017; Wynants et al., 2017, 2018). Swarming season and plucking had no effect on any alpha diversity index of $R$. differens (Table 2), except the Shannon-Wiener index of non-plucked grasshoppers in Fort Portal that was significantly lower than that of plucked and non-plucked $R$. differens from other regions. Given that a lower Shannon-Wiener index is associated with a lower diversity (Di Bitetti, 2000), non-plucked R. differens from Fort Portal had the lowest diversity of microorganisms. The manual plucking may be hypothesized to introduce new types of microorganisms in the food, but this was not reflected by the diversity indices as a general trend. In addition, there was no significant difference between the observed and estimated (Chao1) richness of OTUs (Table 2). Additionally, based on the Chao1 estimator, the sample coverage ranged from 96.56 to $99.79 \%$, indicating that our sequencing depth was sufficient enough to accurately characterize the bacterial communities. The most abundant OTUs of plucked and non-plucked $R$. differens from each of the three trading points of each geographical area source for each swarming season are shown in Figs. 4-6. Only OTUs with an abundance of equal to or more than $2.5 \%$ were considered for presentation. OTUs $1,2,3,4,5,6,7,8$ $10,12,13,14,1533$, and 605 belonging to genera Staphylococcus, Undibacterium, Lactococcus, Buttiauxella, Acinetobacter, Micrococcus, Weissella, Enterococcus, Leuconostoc, Kurthia, and Enhydrobacter were present in $R$. differens grasshoppers from all geographic areas. Among these, OTUs $1,2,3,4,5$, and 605 were the most abundant. As these bacterial genera can easily be cultivated under standard laboratory

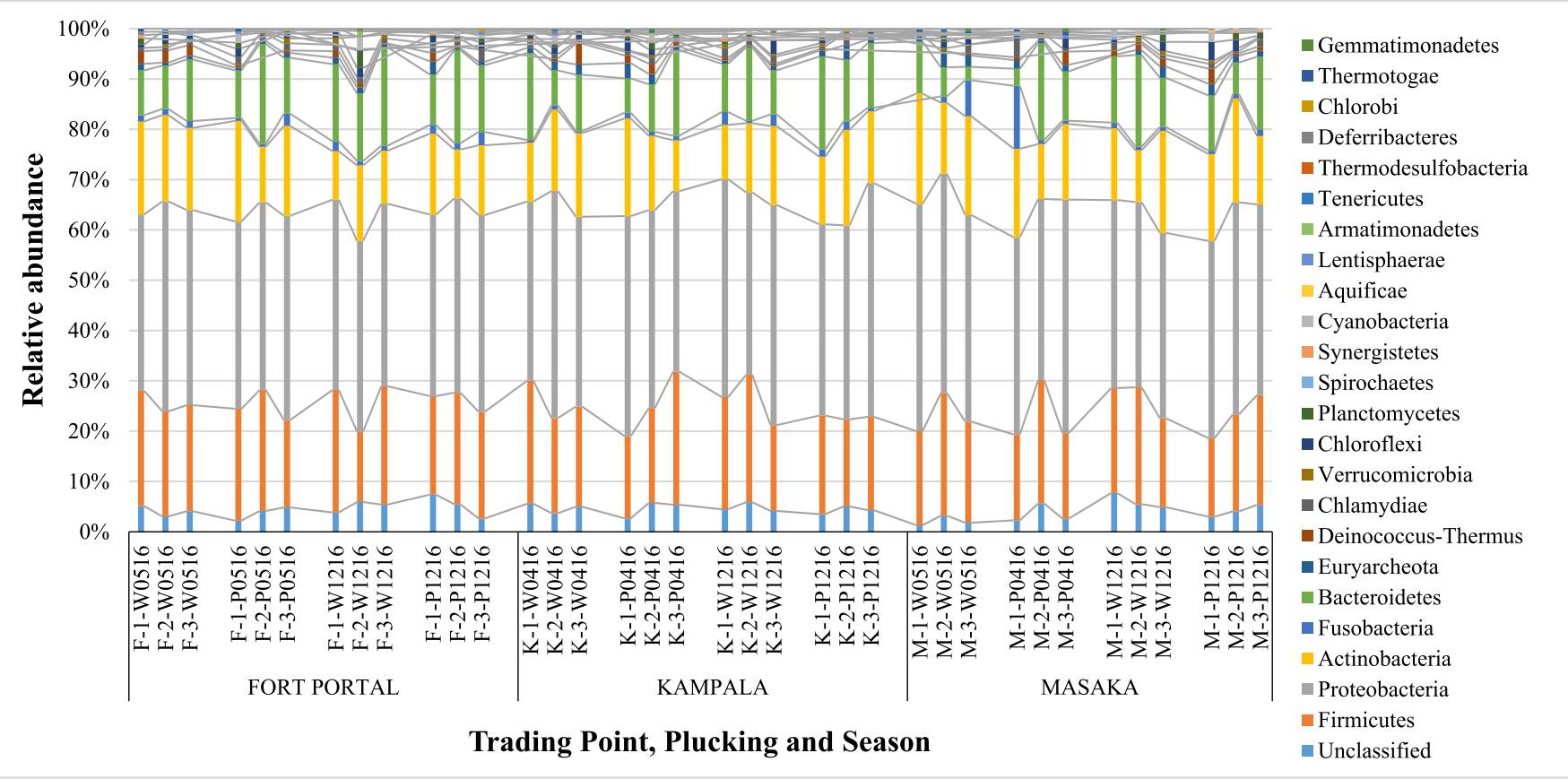

Fig. 3. Relative abundance (\%) of bacterial phyla present in samples of raw plucked (P) and non-plucked (W) Ruspolia differens obtained from each of the three trading points in the geographical areas of Fort Portal (F), Kampala (K) and Masaka (M) districts, in the two swarming seasons of March-May 2016 (04/0516) and November-December 2016 (1216). 
Table 2

Effect of season, sourcing geographical area and plucking on selected alpha diversity indices of $R$. differens.

\begin{tabular}{|c|c|c|c|c|c|c|c|}
\hline \multirow[t]{2}{*}{ Geographical area } & \multirow[t]{2}{*}{ Season } & \multirow[t]{2}{*}{ Plucking Treatment } & \multicolumn{5}{|l|}{ Alpha diversity index } \\
\hline & & & Richness & Chao1 & Good's Coverage & Shannon-Wiener & Evenness \\
\hline \multirow[t]{4}{*}{ Fort Portal } & \multirow[t]{2}{*}{ Nov-Dec } & Non-plucked & $421.00 \pm 274.27^{c}$ & $421.90 \pm 274.26^{\mathrm{c}}$ & $99.79 \pm 0.36^{\mathrm{c}}$ & $4.02 \pm 0.26^{\mathrm{c}}$ & $0.69 \pm 0.11^{\mathrm{c}}$ \\
\hline & & Plucked & $235.33 \pm 89.11^{c}$ & $236.47 \pm 89.75^{c}$ & $99.53 \pm 0.26^{\mathrm{c}}$ & $3.32 \pm 1.11^{\mathrm{c}}$ & $0.61 \pm 0.18^{c}$ \\
\hline & \multirow[t]{2}{*}{ Mar-My } & Non-plucked & $155.67 \pm 8.08^{c}$ & $161.30 \pm 10.08^{\mathrm{c}}$ & $96.56 \pm 2.17^{\mathrm{c}}$ & $2.90 \pm 1.21^{\mathrm{d}}$ & $0.57 \pm 0.03^{c}$ \\
\hline & & Plucked & $249.67 \pm 97.42^{c}$ & $251.33 \pm 97.89^{c}$ & $99.32 \pm 0.08^{\mathrm{c}}$ & $3.46 \pm 0.56^{\mathrm{c}}$ & $0.63 \pm 0.08^{c}$ \\
\hline \multirow[t]{4}{*}{ Kampala } & \multirow[t]{2}{*}{ Nov-Dec } & Non-plucked & $277.00 \pm 159.69^{c}$ & $282.77 \pm 158.30^{c}$ & $97.67 \pm 3.63^{c}$ & $4.30 \pm 0.36^{c}$ & $0.78 \pm 0.04^{c}$ \\
\hline & & Plucked & $220.67 \pm 107.72^{c}$ & $221.73 \pm 107.13^{c}$ & $99.34 \pm 0.89^{c}$ & $3.37 \pm 0.63^{c}$ & $0.64 \pm 0.17^{c}$ \\
\hline & \multirow{2}{*}{ Mar-My } & Non-plucked & $284.00 \pm 95.22^{\mathrm{d}}$ & $287.33 \pm 94.31^{\mathrm{d}}$ & $98.74 \pm 1.68^{\mathrm{c}}$ & $3.57 \pm 0.29^{c}$ & $0.63 \pm 0.04^{c}$ \\
\hline & & Plucked & $318.33 \pm 111.97^{c}$ & $319.27 \pm 112.62^{\mathrm{c}}$ & $99.73 \pm 0.12^{\mathrm{c}}$ & $3.99 \pm 0.56^{\mathrm{c}}$ & $0.69 \pm 0.06^{\mathrm{c}}$ \\
\hline \multirow[t]{4}{*}{ Masaka } & \multirow[t]{2}{*}{ Nov-Dec } & Non-plucked & $290.00 \pm 120.80^{c}$ & $291.73 \pm 120.94^{c}$ & $99.34 \pm 0.36^{c}$ & $3.91 \pm 0.18^{c}$ & $0.69 \pm 0.06^{c}$ \\
\hline & & Plucked & $313.67 \pm 95.30^{c}$ & $314.67 \pm 95.22^{c}$ & $99.65 \pm 0.20^{c}$ & $3.57 \pm 0.56^{\mathrm{c}}$ & $0.62 \pm 0.11^{\mathrm{c}}$ \\
\hline & \multirow[t]{2}{*}{ Mar-My } & Non-plucked & $177.33 \pm 37.81^{\mathrm{c}}$ & $180.13 \pm 38.25^{c}$ & $98.44 \pm 0.42^{\mathrm{c}}$ & $3.22 \pm 0.49^{c}$ & $0.63 \pm 0.12^{c}$ \\
\hline & & Plucked & $236.00 \pm 123.47^{c}$ & $239.17 \pm 122.94^{c}$ & $98.37 \pm 1.89^{c}$ & $2.88 \pm 0.65^{c}$ & $0.53 \pm 0.11^{\mathrm{c}}$ \\
\hline
\end{tabular}

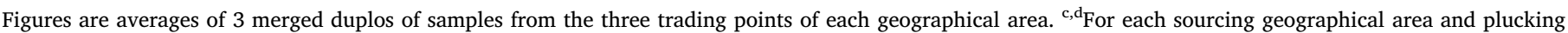

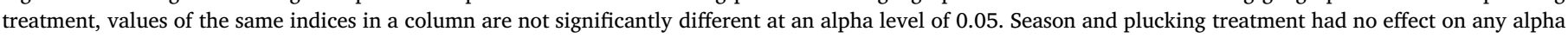

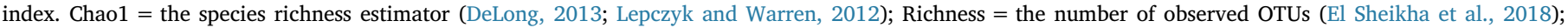

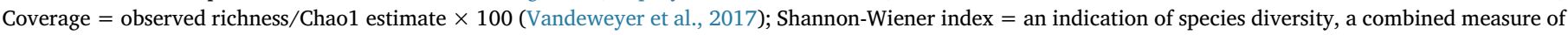

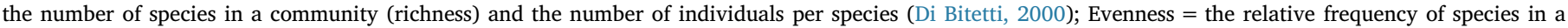
community (Di Bitetti, 2000).

conditions (Batt and Tortorello, 2014; Eder et al., 2011; Elliott and Facklam, 1993; Falkow et al., 2006; Kamboj et al., 2015; Klijn et al., 1995; PHE, 2014), it may be expected that they account for the high total aerobic counts observed (Patil and Muskan, 2009). In addition, they are also involved in the spoilage of various types of foods (Sperber and Doyle, 2009), thus possibly responsible for microbial spoilage of $R$. differens. Most probably, bacteria such as Lactococcus (OTUs 2 and 605), Enterococcus (OTU 10), Leuconostoc (OTU 12) and Weissella (OTUs 8 and 13) contributed to the high lactic acid bacteria counts presented in Table S2. Buttiauxella (OTU 4, belonging to the Enterobaceriaceae) was one of the most abundant genera in $R$. differens grasshoppers from all geographical areas. Erwinia (OTU 935, also belonging to the Enterobaceriaceae) was present in grasshoppers from Masaka and Kampala. In addition to these two, also other Enterobacteriaceae that were less abundant $(\leq 2.5 \%)$ but culturable, are possibly responsible for the high Enterobacteriaceae counts. The abundance of OTUs belonging to the LAB genera was higher than those belonging to the Enterobacteriaceae, explaining why the former had higher counts than the latter. The high aerobic spore count could be resulting from the OTUs belonging to the Bacillus and Clostridium genera, which were present in the 'other species', whose abundance was below $\leq 2.5 \%$. 'Other species' comprised of $20-60 \%$ of the OTUs in $R$. differens from Fort Portal, $30-82 \%$ of $R$.

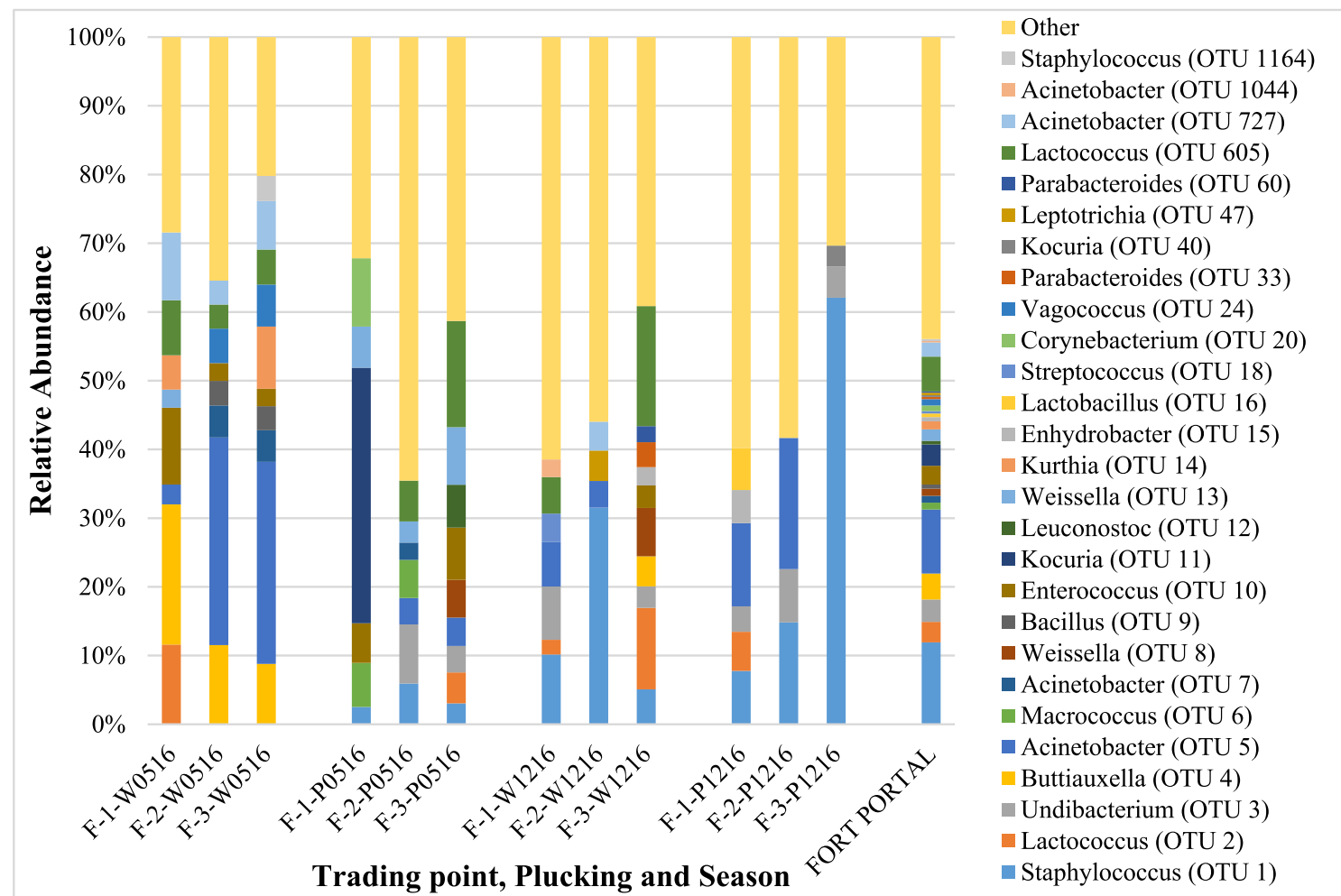

Fig. 4. Relative abundance (\%) of Operational Taxonomic Units (OTUs) present in samples of raw plucked (P) and non-plucked (W) Ruspolia differens obtained from three trading points $(1=$ Kikaali, $2=$ Kisenyi and 3 = Kabatu) in Fort Portal (F) district, in the two swarming seasons of March-May (0516) and November-December (1216) of the year 2016. 


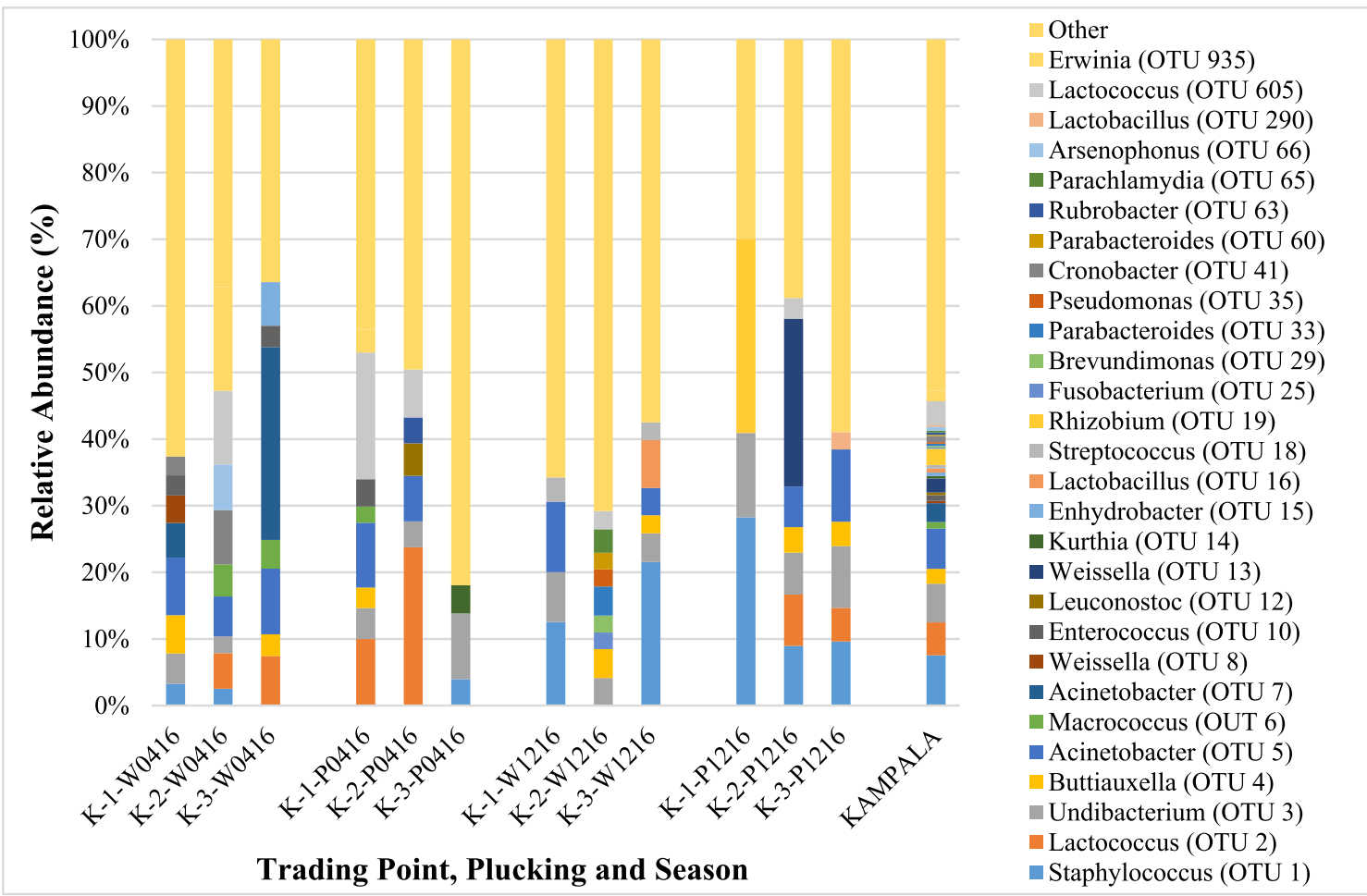

Fig. 5. Relative abundance (\%) of Operational Taxonomic Units (OTUs) present in samples of raw plucked (P) and non-plucked (W) Ruspolia differens obtained from three trading points $(1=$ Kasubi, 2 = Nateete and 3 = Busega) in Kampala (K) district, in the two swarming seasons of March-May (0416) and November-December (1216) of the year 2016.

differens from Kampala and 19-51\% of $R$. differens from Masaka. This implies that 'other' OTUs were on many occasions abundant and thus if culturable, reasonably contributing to the observed microbial counts.

Some OTUs were specific to some geographical areas, trading points, swarming seasons and plucking, thus greatly contributing to the observed bacterial species richness and abundance in $R$. differens. For example, in the March-May swarming season, a species identified as Bacillus anthracis/B. cereus/B. thuringensis (OTU 9) was found in non-

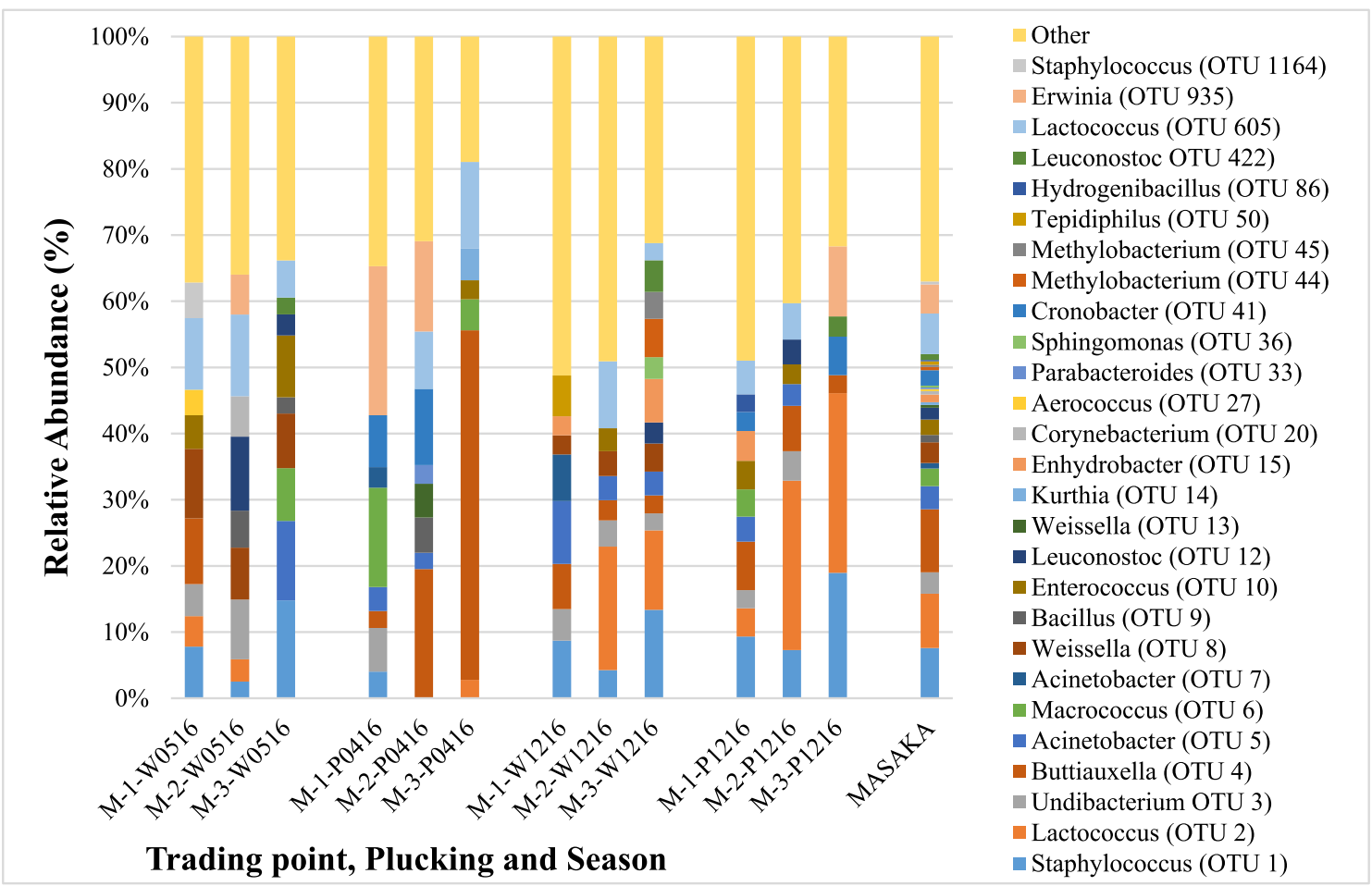

Fig. 6. Relative abundance (\%) of Operational Taxonomic Units (OTUs) present in samples of raw plucked (P) and non-plucked (W) Ruspolia differens obtained from three trading points $(1=$ Kayirikiti, $2=$ Kitaka and $3=$ Masaka town) in Masaka (M) district, in the two swarming seasons of March-May (04/0516) and November-December (1216) of the year 2016. 

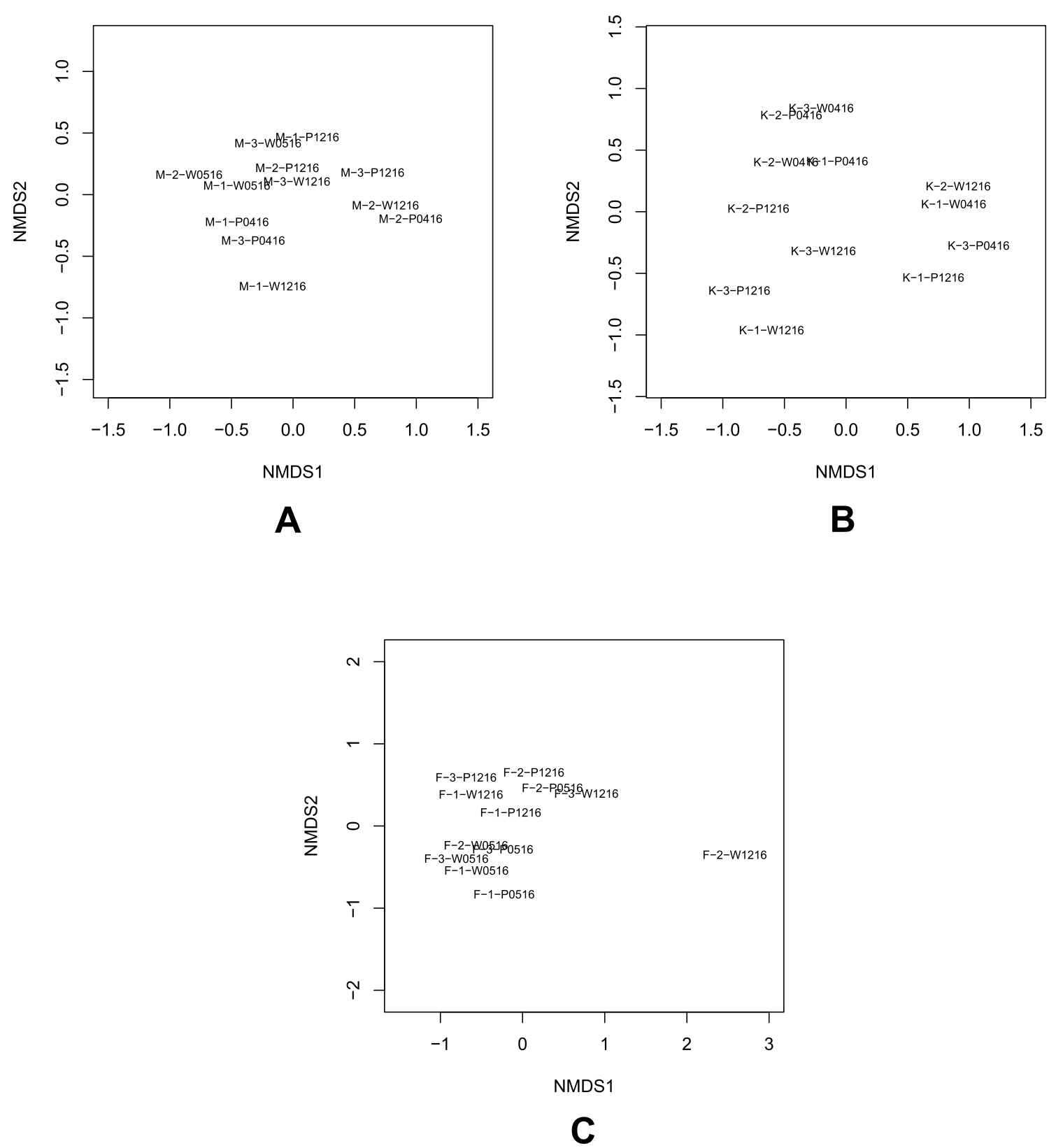

Fig. 7. Non-metric multidimensional scaling (NMDS) ordinations composed of the bacterial community composition data for raw plucked (P) and non-plucked (W) $R$. differens from the three trading points (1, 2 \& 3) of Masaka (M), (Fig. 7A: Stress value 0.128), Kampala (Fig. 7B; Stress value 0.076) and Fort Portal (F) (Fig. 7C; Stress value 0.092), in the two swarming seasons of March-May (04/0516) and November-December (1216) of the year 2016. The distance between different points on the plot reflects their similarity level, i.e., the more similar the bacterial communities, the smaller the distance between the points. Plots were constructed based on the bacterial community data for the most abundant OTUs.

plucked $R$. differens from two of the three trading points in Masaka and Fort Portal. No distinction can be made between these three species using the Illumina Miseq sequencing approach applied in this study, as the sequence used for identification is the same in each of this species. Further research on the occurrence and deeper identification of these Bacillus species, e.g. involving PCR using specific primers is a strong necessity. Corynebacterium (OTU 20) was found in plucked and nonplucked $R$. differens in one of the trading points in Fort Portal and Masaka respectively. Lactobacillus (OTU 16) and Streptococcus (OTU 18) were found in plucked and non-plucked $R$. differens in Fort Portal and Kampala in the December-November swarming season. From Fort Portal and Masaka in the March-May swarming season, Staphylococcus sciuri (OTU 1164) was identified in non-plucked R. differens. Similarly, OTUs 11, 24, 40, 47, 727 and 1044 were only found in Fort Portal;
OTUs 19, 25, 29, 35, 41, 63, 65, 66 and 290 only in Kampala; and OTUs 27, 36, 41, 44, 45, 50, 86, and 422 only in Masaka. This implies that without collection of $R$. differens from the major trading points of the different geographical areas of source and for the various swarming seasons, the $R$. differens microbial species richness and diversity would be underestimated. NMDS ordination of $R$. differens from Masaka (Fig. 7A), Kampala (Fig. 7B) and Fort Portal (Fig. 7C) show no clear differences in the bacterial composition with regard to trading point, swarming season and plucking.

\subsection{Safety significance of identified operational taxonomic units}

Some OTUs identified in $R$. differens correspond to genera harbouring potential pathogens including the genera Bacillus, Clostridium 
and Staphylococcus that belong to the phylum Firmicutes, and the genera Acinetobacter, Buttiauxella, Campylobacter, Neisseria and Pseudomonas that belong to the phylum Proteobacteria. Unlike the other genera, members of the Clostridium and Campylobacter genera have also been identified in other edible insects (Belluco et al., 2015; Garofalo et al., 2017). Bacteria in the genus Staphylococcus may be pathogens of humans and animals including $S$. aureus, and $S$. argenteus which has been previously described as a less virulent divergent lineage of $S$. aureus (Foster, 1996; Schuster et al., 2017; Thaipadungpanit et al., 2015). OTU 1 showing a high 16S rRNA gene similarity with $S$. argentus was found in this study though further research is needed to confirm its identity. Additionally, a Buttiauxella species such as Buttiauxella agrestis (high 16S rRNA sequence similarity with OTU 4) has been associated with post-caesarean surgical site infections in humans (Antonello et al., 2014). Some species of Bacillus are harmful to humans, plants or other organisms. For example, species such as B. anthracis, B. cereus and $B$. thuringensis have toxic effects that could be fatal in human beings (Chase, 2017; Helgason et al., 2000; Spencer, 2003). In this study, OTU 9 with a high 16 S rRNA gene similarity with $B$. anthracis/B. cereus/B. thuringensis was observed. Some species of the genus Vagococcus such as $V$. fluvialis have been implicated in causing infective endocarditis in humans in a fulminant way (Abuzaanona et al., 2016). An OTU with a high 16S rRNA gene similarity with $V$. fluvialis (OTU 24) was detected in this study.

Other less abundant $(\leq 2.5 \%)$ OTUs belonging to genera with the potential to cause food borne diseases were also found. Members of the genus Clostridium may cause life threatening infections such as septic arthritis, osteomyelitis, soft tissue infection, abdominal infections, brain abscess, endocarditis, autism, and colitis (Edagiz et al., 2015; Elsayed and Zhang, 2005; Pequegnat et al., 2013; Leffler and Lamont, 2015; Surawicz et al., 2013). Metagenetic analysis showed OTU's with 16S rRNA gene similarity with $C$. bifermentans (OTU 21), C. intestinale (OTU 764), C. bolteae (OTU 1212) and C. difficile (OTU 1609). Members of the genus Campylobacter are associated with severe fatal invasive infections and the inflammatory bowel disease (Lam et al., 2011; Mahlen and Clarridge, 2009). This study revealed OTUs with a high 16S rRNA gene similarity with $C$. rectus (OTU 105) and C. concisus (OTU 753). Members of the genera Pseudomonas, Acinetobacter and Neisseria may cause various nosocomical and sometimes fatal infections in immunocompromised humans (Bayhan et al., 2014; Dortet et al., 2006; Doublet et al., 2010; Gellatly and Hancock, 2013; Gierhart and Chukwuma, 2015; Huang et al., 2014). This study revealed OTUs with a high 16S rRNA gene similarity with Pseudomonas aeruginosa (OTU 1061), P. luteola (OTU, 1468), A. ursingii (OTU 1044), and N. flavescens (OTU 1599). These findings are of concern. Further research is needed to confirm the identity of the OTUs found in $R$. differens with a high $16 \mathrm{~S}$ rRNA similarity with human pathogenic microorganisms.

\subsection{Potential beneficial health effects of some bacteria genera}

Some bacteria genus identified in $R$. differens are associated with beneficial effects to human health. Some bacteria belonging to lactic acid bacteria (Leuconostoc, Lactococcus, Lactobacillus, Streptococcus) and Bacillus may confer health benefits to humans if ingested in sufficient amounts (Fijan, 2014). Beneficial health effects of LAB strains and their fermented products include preventing or ameliorating lactose intorelance, diarrhoea, infections, allergies, intestinal disorders and some types of cancer (del Carmen et al., 2012). S. dentisani may impact human health positively by playing a role in inhibiting the growth of major oral pathogens through the production of bacteriocins and by buffering an acidic $\mathrm{pH}$, the latter being the primary cause of dental caries (López-López et al., 2017). To this regard, an OTU with a high $16 \mathrm{~S}$ rRNA similarity to $S$. dentisani (OTU 18) was found, but further research is needed to confirm its identity. The presence of lactic acid bacteria (Leuconostoc, Lactococcus, Lactobacillus and Streptococcus) also indicates the potential for using lactic fermentation as one of the preservation options for $R$. differens. Fermentation processes are known to enhance the nutritional quality of foods, since in the process, fermenting microorganisms synthesize vitamins and minerals and produce biologically active substances such as beneficial peptides (Şanlier et al., 2017) that enhance the nutritional value of the fermented food among other advantages. It has been demonstrated that mealworms can be fermented when they are pulverized and when using a commercial meat starter culture (Borremans et al., 2018). The possibility of fermenting $R$. differens into novel food products with enhanced nutritional benefits has not been documented in scientific literature yet and remains to be explored.

\section{Conclusions}

In this study, the microbial quality, bacterial diversity and intrinsic properties $(\mathrm{pH}$, water activity and moisture content) of $R$. differens after harvesting in the wild in different geographical regions in Uganda and in different seasons were characterised. The intrinsic properties were similar to those of other fresh edible insects and other protein-rich foods such as meat and fish from various countries in Europe. The counts of all culturable microbial groups assayed were comparable to those of other edible insect species, except for the total aerobic spore count that was significantly higher. There is an urgent need to define microbial criteria for edible insects with respect to microorganisms of food quality and food safety concern. The geographical area of source, trading point, swarming season and plucking influenced the microbial quality of $R$. differens and proved that it was necessary so as to create a more correct estimate of its bacterial diversity and species' richness. Proteobacteria and Firmicutes were the predominant phyla detected, which were the most abundant OTUs. The coverage range of 96.56-99.79\% indicated that almost all OTUs expected to be present in all samples were identified. The high microbial counts in combination with the favourable intrinsic properties highly predispose $R$. differens to rapid microbial spoilage. When not properly handled and appropriately heat treated, $R$. differens is likely to cause food borne diseases due to the presence of potential human pathogenic microorganisms, mostly from the genera Clostridium and Campylobacter. In contrast, Streptococcus dentisani and lactic acid bacterial may be beneficial to human health. There is a need to: (i) use other techniques such as the Specific Spoilage Organism (SSO) concept to identify the specific spoilage microorganisms of fresh $R$. differens, (ii) analyse $R$. differens for the presence of fungi of food safety concern such as mycotoxigenic fungi, (iii) confirm the identity of OTUs with a high 16S rRNA similarity to animal and human pathogenic microorganisms, (iv) investigate the ability of $R$. differens to allow and support growth and survival of known food pathogens during storage, and (v) investigate potential beneficial health effects of especially the lactic acid bacteria of $R$. differens.

\section{Declarations of interest}

None.

\section{Acknowledgements}

This work was financially supported by a scholarship from the KU Leuven Interfaculty Council for Development Cooperation (IRO), the INSFEED Project and by an FWO travel grant.

\section{Appendix A. Supplementary data}

Supplementary data related to this article can be found at https:// doi.org/10.1016/j.fm.2018.09.005.

\section{References}

Abuzaanona, A., Darzi, W. Al, Nour, K.A., 2016. Vagococcus fluvialis causing severe 
infective endocarditis presenting with embolic stroke: a case report. J. Clin. Exp. Cardiol. 7, 8-44.

Agea, J., Biryomumaisho, D., Buyinza, M., Nabanoga, G., 2008. Commercialization of Ruspolia nitidula (nsenene grasshoppers) in central Uganda. Afr. J. Food Nutr. Sci. 8, 319-332.

Amadi, E., Kiin-kabari, D., 2016. Nutritional composition and $\mathrm{m}$ of some edible Insects commonly eaten in Africa, hurdles and future Prospects: a critical review. J. Food Microbiol. Saf. Hyg. 1, 1-7.

Antonello, V.S., Dallé, J., Domingues, G.C., Ferreira, J.A.S., Fontoura, M. do C.Q., Knapp, F.B., 2014. Post-cesarean surgical site infection due to Buttiauxella agrestis. Int. J. Infect. Dis. 22, 65-66.

Batt, C.A., Tortorello, M.L., 2014. Encyclopedia of Food Microbiology, second ed. CRC Press: Taylor \& Francis Group, Florida.

Bayhan, G.I., Senel, S., Tanir, G., Ozkan, S., 2014. Bacteremia Caused by Pseudomonas luteola in pediatric patients. Jpn. J. Infect. Dis. 68, 50-54.

Belluco, S., Losasso, C., Maggioletti, M., Alonzi, C., Ricci, A., Paoletti, M.G., 2015. Edible insects: a food security solution or a food safety concern? Anim. Front. 5, 25-30.

Bokulich, N.A., Lewis, Z.T., Boundy-Mills, K., Mills, D.A., 2016. A new perspective on microbial landscapes within food production. Curr. Opin. Biotechnol. 37, 182-189.

Borremans, A., Lenaerts, S., Crauwels, S., Lievens, B., Van Campenhout, L., 2018. Marination and fermentation of yellow mealworm larvae (Tenebrio molitor). Food Contr. 92, 47-52.

Brits, J.A., Thornton, C.H., 1981. On the biology of Ruspolia differens (serville) (Orthoptera: Tettigoniidae) in South Africa. Phytophylactica 13, 169-173.

Brown, S.P., Veach, A.M., Rigdon-Huss, A.R., Grond, K., Lickteig, S.K., Lothamer, K., Oliver, A.K., Jumpponen, A., 2015. Scraping the bottom of the barrel: are rare high throughput sequences artifacts? Fungal Ecol 13, 221-225.

Caporaso, J.G., Lauber, C.L., Walters, W.A., Berg-Lyons, D., Lozupone, C.A., Turnbaugh, P.J., Fierer, N., Knight, R., 2011. Global patterns of 16S rRNA diversity at a depth of millions of sequences per sample. Proc. Natl. Acad. Sci. Unit. States Am. 108, 4516-4522.

Chase, C., 2017. Blackwell's Five-minute Veterinary Consult. Ruminant, second ed. John Wiley \& Sons, Inc., New Jersy.

Deák, T., Farkas, J., 2013. Microbiology of Thermally Preserved Foods: Canning and Novel Physical Methods. DEStech Publications, Pennysylvania.

del Carmen, S., de Moreno de LeBlanc, A., Miyoshi, A., Azevedo, V., Bermudez-Humaran, L., Langella, P., LeBlanc, J., 2012. Anti-inflamatory properties of genetically modified lactic acid bacteria. In: Watson, R.R., Ronald, R., Preedy, V.R. (Eds.), Bioactive Food as Interventions for Arthritis and Related Inflammatory Diseases. Academic Press, Cambidge, MA, pp. 680.

DeLong, E.F., 2013. Microbial Metagenomics, Metatranscriptomics, and Metaproteomics. Academic Press, San Diego, CA.

Di Bitetti, M.S., 2000. The distribution of grooming among female primates: testing hypotheses with the Shannon-Wiener diversity index. Beyond Behav. 137, 1517-1540.

Dijk, R., van den Berg, D., Beumer, R.R., de Boer, E., Dijkstra, A.F., Kalkman, P. Stegeman, H., Uyttendaele, M., 2015. Microbiologie van voedingsmiddelen: methoden, principes en criteria. Noordvliet Media BV, Houten.

Dortet, L., Legrand, P., Soussy, C.-J., Cattoir, V., 2006. Bacterial identification, clinical significance, and antimicrobial susceptibilities of Acinetobacter ursingii and Acinetobacter schindleri, two frequently misidentified opportunistic pathogens. J. Clin. Microbiol. 44, 4471-4478.

Doublet, B., Robin, F., Casin, I., Fabre, L., Le Fleche, A., Bonnet, R., Weill, F.X., 2010. Molecular and biochemical characterization of the natural chromosome-encoded class A B-lactamase from Pseudomonas luteola. Antimicrob. Agents Chemother. 54, $45-51$.

Edagiz, S., Lagace-Wiens, P., Embil, J., Karlowsky, J., Walkty, A., 2015. Empyema caused by Clostridium bifermentans: a case report. Can. J. Infect Dis. Med. Microbiol. 26, 105-107.

Eder, W., Wanner, G., Ludwig, W., rgen Busse, H.-J., Ziemke-Kä geler, F., Lang, E., Wolfgang Eder, C., 2011. Description of Undibacterium oligocarboniphilum sp. nov., isolated from purified water, and Undibacterium pigrum strain CCUG 49012 as the type strain of Undibacterium parvum sp. nov., and emended descriptions of the genus Undibacterium and the species Undibacterium pigrum. Int. J. Syst. Evol. Microbiol. 61, 384-391.

Edgar, R.C., 2016. SINTAX: a Simple Non-Bayesian Taxonomy Classifier for 16 S and ITS Sequences. https://www.biorxiv.org/content/biorxiv/early/2016/09/09/074161. full.pdf, Accessed date: 27 April 2018.

Edgar, R.C., 2013. UPARSE: highly accurate OTU sequences from microbial amplicon reads. Nat. Methods 10, 996-998.

Elliott, J.A., Facklam, R.R., 1993. Identification of Leuconostoc spp. by analysis of soluble whole-cell protein patterns. J. Clin. Microbiol. 31, 1030-1033.

Elsayed, S., Zhang, K., 2005. Bacteremia caused by Clostridium intestinale. J. Clin. Microbiol. 43, 2018-2020.

El Sheikha, A.F., Levin, R.E., Xu, J., 2018. Molecular Techniques in Food Biology: Safety, Biotechnology, Authenticity and Traceability. John Wiley \& Sons, Ltd., Chichester, UK.

Falkow, S., Rosenberg, E., Schleifer, K.-H., Stackebrandt, E., 2006. The prokaryotes. In: Proteobacteria: Gamma Subclass: a Handbook on the Biology of Bacteria, vol. 6 Springer, Minnesota.

Fijan, S., 2014. Microorganisms with claimed probiotic properties: an overview of recent literature. Int. J. Environ. Res. Publ. Health 11, 4745-4767.

Finke, M.D., 2015. Complete nutrient content of four species of commercially available feeder insects fed enhanced diets during growth. Zoo Biol. 34, 554-564.

Foster, T., 1996. Staphylococcus. In: Baron, S. (Ed.), Medical Microbiology, fourth ed. The University of Texas medical branch at Galveston, Galveston, TX (chapter 12).

Garofalo, C., Osimani, A., Milanović, V., Taccari, M., Cardinali, F., Aquilanti, L., Riolo, P.,
Ruschioni, S., Isidoro, N., Clementi, F., 2017. The microbiota of marketed processed edible insects as revealed by high-throughput sequencing. Food Microbiol. 62, 15-22.

Gellatly, S.L., Hancock, R.E.W., 2013. Pseudomonas aeruginosa: new insights into pathogenesis and host defenses. Pathog. Dis. 67, 159-173.

Gierhart, S., Chukwuma, U., 2015. Annual Surveillance Summary: Pseudomonas aeruginosa Infections in the Military Health System (MHS). Military Health System (MHS), Washington DC.

Gomba, A., Chidamba, L., Korsten, L., 2017. Effect of postharvest practices including degreening on citrus carpoplane microbial biomes. J. Appl. Microbiol. 122, 1057-1070.

Gurevich, A., Saveliev, V., Vyahhi, N., Tesler, G., 2013. QUAST: quality assessment tool for genome assemblies. Bioinformatics 29, 1072-1075.

Harrison, J.A., 2017. Food Safety for Farmers Markets: a Guide to Enhancing Safety of Local Foods. Springer International Publishing AG, Cham, Switzerland.

Helgason, E., Okstad, O.A., Caugant, D.A., Johansen, H.A., Fouet, A., Mock, M., Hegna, I., Kolstø, A.B., 2000. Bacillus anthracis, Bacillus cereus, and Bacillus thuringiensis-one species on the basis of genetic evidence. Appl. Environ. Microbiol. 66, 2627-2630.

Huang, L., Ma, L., Fan, K., Li, Y., Xie, L., Xia, W., Gu, B., Liu, G., 2014. Necrotizing pneumonia and empyema caused by Neisseria flavescens infection. J. Thorac. Dis. 6, $553-557$.

Hui, Y.H., Sattar, S.A., Nip, W.-K., 2001. Foodborne Disease Handbook, second ed. Marcel Dekker, Inc., New York.

Hui, Y.H., Sherkat, F., 2005. Handbook of Food Science, Technology, and Engineering. CRC Press: Taylor \& Francis Group, Florida.

Kamboj, K., Vasquez, A., Balada-Llasat, J.-M., 2015. Identification and significance of Weissella species infections. Front. Microbiol. 6, 1-7.

Kelemu, S., Niassy, S., Torto, B., Fiaboe, K., Affognon, H., Tonnang, H., Maniania, N.K., Ekesi, S., 2015. African edible insects for food and feed: inventory, diversity, commonalities and contribution to food security. J. Insects for Food and Feed 1, 103-119.

Kinyuru, J.N., Kenji, G.M., Njoroge, S.M., 2009. Nutritional potential of longhorn grasshopper (Ruspolia differens) consumed in lake Victoria region of East Africa. J. Agric. Sci. Technol. 1, 32-46.

Klijn, N., Weerkamp, A.H., De Vos, W.M., 1995. Detection and characterization of lactoseutilizing Lactococcus spp. in natural ecosystems. Appl. Environ. Microbiol. 61 788-792.

Klunder, H.C., Wolkers-rooijackers, J., Korpela, J.M., Nout, M.J.R., 2012. Microbiological aspects of processing and storage of edible insects. Food Contr. 26, 628-631.

Kozich, J.J., Westcott, S.L., Baxter, N.T., Highlander, S.K., Schloss, P.D., 2013. Development of a dual-index sequencing strategy and curation pipeline for analyzing amplicon sequence data on the miseq illumina sequencing platform. Appl. Environ. Microbiol. 79, 5112-5120.

Lam, J.Y.W., Wu, A.K.L., Ngai, D.C., Teng, J.L.L., Wong, E.S.Y., Lau, S.K.P., Lee, R.A., Woo, P.C.Y., 2011. Three cases of severe invasive infections caused by Campylobacter rectus and first report of fatal C. rectus infection. J. Clin. Microbiol. 49, 1687-1691.

Leff, J.W., Fierer, N., 2013. Bacterial communities associated with the surfaces of fresh fruits and vegetables. PLoS One 8, 1-9.

Leffler, D.A., Lamont, J.T., 2015. Clostridium difficile infection. N. Engl. J. Med. 16, 1539-1548.

Lepczyk, C.A., Warren, P.S., 2012. Urban Bird Ecology and Conservation. University of California Press, Berkeley, CA.

López-López, A., Camelo-Castillo, A., Ferrer, M.D., Simon-Soro, áurea, Mira, A., 2017. Health-associated niche inhabitants as oral probiotics: the case of Streptococcus dentisani. Front. Microbiol. 8, 1-12.

Lovell, T., 2012. Nutrition and Feeding of Fish, second ed. Springer Science \& Business Media, New York.

Mahlen, S.D., Clarridge, J.E., 2009. Oral abscess caused by Campylobacter rectus: case report and literature review. J. Clin. Microbiol. 47, 848-851.

Massa, B., 2015. Taxonomy and distribution of some katydids (Orthoptera Tettigoniidae) from tropical Africa. ZooKeys 524, 17-44.

Matojo, N.D., 2017. A review work on how to differentiate the longhorn grasshoppers Ruspolia differens and Ruspolia nitidula (Orthoptera: Tettigoniidae). J. Appl. Life Sci. Int. 15, 1-4.

Matojo, N.D., Hosea, K.M., 2013. Phylogenetic relationship of the longhorn grasshopper Ruspolia differens Serville (Orthoptera: Tettigoniidae) from Northwest Tanzania based on $18 \mathrm{~S}$ ribosomal nuclear sequences. J. Insects 504285, 1-5.

Matojo, N.D., Njau, M.A., 2010. Plasticity and biosystematics of swarming of the conehead Ruspolia differens Serville (Orthoptera: Conocephalidae) study site. Int. J. Integr. Biol. 9, 97-103.

Mccrae, A.W.R., 1982. Characteristics of swarming in the African edible bush-cricket Ruspolia differens (serville) (Orthoptera, Tettigonioidea). J. East Afr. Nat. Hist. Soc. Natl. Mus. 1-56 1982.

Megido, R.C., Desmedt, S., Blecker, C., Béra, F., Haubruge, É., Alabi, T., Francis, F., 2017. Microbiological load of edible insects found in Belgium. Insects 8, 1-8.

Monaghan, J., 2010. Monitoring Microbial Food Safety of Fresh Produce. Agriculture and Horticulture Development Board, Warwickshire, U.K.

Nielsen, S.S., 2010. Food Analysis Laboratory Mannual, second ed. Springer Sciennce + Business Media LLC, New York, U.S.A.

Osimani, A., Garofalo, C., Milanovic, V., Taccari, M., Cardinali, F., Aquilanti, L., Pasquini, M., Mozzon, M., Raffaelli, N., Ruschioni, S., Riolo, P., Isidoro, N., Clementi, F., 2016. Insight into the proximate composition and microbial diversity of edible insects marketed in the European Union. Eur. Food Res. Technol. 243, 1157-1171.

Patil, U.K., Muskan, K., 2009. Essentials of Biotechnology. I.K. International Publishing House, New Delhi.

Pequegnat, B., Sagermann, M., Valliani, M., Toh, M., Chow, H., Allen-Vercoe, E., Monteiro, M.A., 2013. A vaccine and diagnostic target for Clostridium bolteae, an autism-associated bacterium. Vaccine 31, 2787-2790. 
Public Health England, PHE, 2014. Identification of Staphylococcus species, Micrococcus species and Rothia species. UK standards for microbiology investigations. Bacteriology 7, 1-32.

R Development Core Team, 2013. R: a Language and Environment for Statistical Computing. R Foundation for statistical computing, Vienna, Austria.

Şanlier, N., Gökcen, B.B., Sezgin, A.C., 2017. Health Benefits of Fermented Foods. https://www.tandfonline.com/doi/full/10.1080/10408398.2017.1383355?scroll= top\&needAccess = true, Accessed date: 3 June 2018.

Schmidt, S.J., Fontana, A.J., 2007. Water activity values of select food ingredients and products. In: Barbosa-Cánovas, G.V., Fontana, A.J., Schmidt, S.J., Labuza, T.P. (Eds.), Water Activity in Foods. Blackwell Publishing and the Institute of Food Technologists, pp. 407-420.

Schuster, D., Rickmeyer, J., Gajdiss, M., Thye, T., Lorenzen, S., Reif, M., Josten, M. Szekat, C., Melo, L.D.R., Schmithausen, R.M., Liégeois, F., Sahl, H.-G., Gonzalez, J.P.J., Nagel, M., Bierbaum, G., 2017. Differentiation of Staphylococcus argenteus (formerly: Staphylococcus aureus clonal complex 75) by mass spectrometry from $S$. aureus using the first strain isolated from a wild African great ape. Int. J. Med. Microbiol. 307, 57-63.

Sharma, P.D., 2007. Microbiology. Rastogi Publications, New Delhi.

Spellman, F.R., Stoudt, M.L., 2013. Environmental Science: Principles and Practices. Scarecrow Press, Inc., Plymouth, UK.

Spencer, R.C., 2003. Bacillus anthracis. J. Clin. Pathol. 56, 182-187.

Sperber, W.H., Doyle, M.P., 2009. Compendium of the Microbiological Spoilage of Food and Beverages. Springer Sciennce + Business Media LLC, New York.

Ssepuuya, G., 2010. Harnesing the Commercial Potential of Ruspolia nitidula for Increased Incomes and Food Security in Uganda. Makerere University, Kampala.

Ssepuuya, G., Aringo, R.O., Nakimbugwe, D., Mukisa, I.M., 2016b. Effect of processing, packaging and storage-temperature based hurdles on the shelf stability of sautéed ready-to-eat Ruspolia nitidula. J. Insects as Food Feed 1, 245-253.

Ssepuuya, G., Mukisa, I.M., Nakimbugwe, D., 2016a. Nutritional composition, quality, and shelf stability of processed Ruspolia nitidula (edible grasshoppers). Food Sci. Nutr. $5,103-112$

Ssepuuya, G., Tanga, C.M., Yekko, I., Sengendo, F., Ndagire, C.T., Fiaboe, K.K.M., Karungi, J., Nakimbugwe, D., 2018. Suitability of egg hatching conditions and commonly available food plants for rearing the long- horned grasshopper Ruspolia differens Serville (Orthoptera: Tettigoniidae). J. Insects as Food Feed 1-10.
Steele, R., 2004. Understanding and Measuring the Shelf-life of Food. Woodhead Publishing Limited, Cambridge.

Stoops, J., Crauwels, S., Waud, M., Claes, J., Lievens, B., Van Campenhout, L., 2016. Microbial community assessment of mealworm larvae (Tenebrio molitor) and grasshoppers (Locusta migratoria migratorioides) sold for human consumption. Food Microbiol. 53, 122-127.

Surawicz, C.M., Brandt, L.J., Binion, D.G., Ananthakrishnan, A.N., Curry, S.R., Gilligan, P.H., McFarland, L.V., Mellow, M., Zuckerbraun, B.S., 2013. Guidelines for diagnosis, treatment, and prevention of Clostridium difficile infections. Am. J. Gastroenterol. 108, 478-498.

Thaipadungpanit, J., Amornchai, P., Nickerson, E.K., Wongsuvan, G., Wuthiekanun, V., Limmathurotsakul, D., Peacock, S.J., 2015. Clinical and molecular epidemiology of Staphylococcus argenteus infections in Thailand. J. Clin. Microbiol. 53, 1005-1008.

ULII, 2008. Fish (Quality Assurance) Rules, 2008. Uganda Legal Information Institute. https://ulii.org/ug/legislation/statutory-instrument/2008/12, Accessed date: 3 January 2018.

Vandeweyer, D., Crauwels, S., Lievens, B., Van Campenhout, L., 2017. Metagenetic analysis of the bacterial communities of edible insects from diverse production cycles at industrial rearing companies. Int. J. Food Microbiol. 261, 11-18.

Vandeweyer, D., Wynants, E., Crauwels, S., Verreth, C., Viaene, N., Claes, J., Lievens, B., Van Campenhout, L., 2018. Microbial dynamics during industrial rearing, processing, and storage of the tropical house cricket (Gryllodes sigillatus) for human consumption. Appl. Environ. Microbiol. 84, 1-13.

Waud, M., Busschaert, P., Ruyters, S., Jacquemyn, H., Lievens, B., 2014. Impact of primer choice on characterization of orchid mycorrhizal communities using $454 \mathrm{pyr}-$ osequencing. Mol. Ecol. Resour. 14, 679-699.

Wynants, E., Crauwels, S., Lievens, B., Luca, S., Claes, J., Borremans, A., Bruyninckx, L., Van Campenhout, L., 2017. Effect of post-harvest starvation and rinsing on the microbial numbers and the bacterial community composition of mealworm larvae (Tenebrio molitor). Innovat. Food Sci. Emerg. Technol. 42, 8-15.

Wynants, E., Crauwels, S., Verreth, C., Gianotten, N., Lievens, B., Claes, J., Van Campenhout, L., 2018. Microbial dynamics during production of lesser mealworms (Alphitobius diaperinus) for human consumption at industrial scale. Food Microbiol. 70, 181-191.

Zimmermann, M., Burgerstein, L., 2001. Burgerstein's Handbook of Nutrition: Micronutrients in the Prevention and Therapy of Disease. Thieme, New York. 